[Review]

\title{
染料敏化太阳电池中 $\mathrm{TiO}_{2} /$ 染料/电解质界面的修饰
}

\author{
李景哲 孔凡太*武国华黄阳陈汪超 戴松元 ${ }^{*}$
}

(中国科学院等离子体物理研究所, 中国科学院新型薄膜太阳电池重点实验室, 合肥 230031)

\begin{abstract}
摘要: 染料敏化太阳电池(DSC)作为新型太阳电池自问世以来受到了广泛关注, 其系统内部的接触界面尤其 是 $\mathrm{TiO}_{2}$ /染料/电解质界面一直是该领域的研究热点. 光敏染料的吸附以及电子的注入、传输和复合都发生在该 界面, 其界面性质对 DSC 性能具有很大影响. 对染料敏化太阳电池中 $\mathrm{TiO}_{2} /$ 染料/电解质界面进行修饰可以有效 抑制染料聚集和电子复合, 提高电子的注入效率与传输速率; 同时, 对 $\mathrm{TiO}_{2}$ 导带边的位置及染料吸附等也产生 一定的影响, 最终提高电池的光电转换效率和稳定性. 本文主要从不同的修饰途径详细评述了 $\mathrm{TiO}_{2} /$ 染料/电解 质界面修饰方法及机理研究进展, 包括 $\mathrm{TiO}_{2}$ 光阳极的修饰改性、染料溶液中共吸附剂的引入和多种染料共敏化 处理以及电解质中不同功能添加剂的应用. 指出了这些修饰方法目前存在的主要问题, 并对未来的发展方向进 行了展望.
\end{abstract}

关键词：染料敏化太阳电池；界面修饰；电子复合；光阳极；共敏化；电解质添加剂；共吸附剂 中图分类号: 0646

\section{$\mathrm{TiO}_{2} /$ Dye/Electrolyte Interface Modification for Dye-Sensitized Solar Cells}

\author{
LI Jing-Zhe KONG Fan-Tai* WU Guo-Hua HUANG Yang \\ CHEN Wang-Chao DAI Song-Yuan*
}

(Key Laboratory of Novel Thin Film Solar Cells, Institute of Plasma Physics, Chinese Academy of Sciences, Hefei 230031, P. R. China)

\begin{abstract}
Dye-sensitized solar cell (DSC), a new type of solar cell, have attracted widespread attention since they were first reported. The internal contact interfaces of DSC, especially $\mathrm{TiO}_{2} /$ dye/electrolyte interfaces, have always been a focus of research in this field. The adsorption of photosensitizers, and the injection, transport, and recombination of photoelectrons, which occur at the interface, have a significant effect on the DSC performance. Modification of the $\mathrm{TiO}_{2} /$ dye/electrolyte interface of DSC can effectively reduce dye aggregation, surpress electronic recombination, enhance electronic injection efficiency, and improve the transport rate, so it improves the photovoltaic performance and stability of the DSC. Modification can also affect the position of $\mathrm{TiO}_{2}$ conduction band, the adsorption behavior of the dye, and other parameters. In this article, researches on the methods and mechanism of $\mathrm{TiO}_{2} /$ dye/electrolyte interface modification are reviewed. These include modification of $\mathrm{TiO}_{2}$ photoanodes by various methods, the introduction of co-adsorbents into the dye bath, the co-sensitization by different dyes, and the use of electrolyte additives with different functional mechanisms in the electrolyte. Finally, problems existed in application of these modification methods and future development directions are discussed.
\end{abstract}

Key Words: Dye-sensitized solar cell; Interface modification; Electronic recombination; Photoanode; Co-sensitization; Electrolyte additive; Coadsorbent

Received: May 3, 2013; Revised: June 17, 2013; Published on Web: June 17, 2013.

*Corresponding authors. KONG Fan-Tai, Email: kongfantai@163.com. DAI Song-Yuan, Email: sydai@ipp.ac.cn; Tel: +86-551-65593222.

The project was supported by the National Key Basic Research Program of China (973) (2011CBA00700), National Natural Science Foundation of China (21003130, 61204075), and External Cooperation Program of the Chinese Academy of Sciences (GJHZ1220).

国家重点基础研究发展规划项目(973) (2011CBA00700), 国家自然科学基金(21003130, 61204075)和中国科学院对外合作重点项目 (GJHZ1220)资助 


\section{1 引 言}

染料敏化太阳电池(DSC)自 1991 年 ${ }^{1}$ 问世以来, 经过近二十年的发展已经取得了很大的进展, 目前 其光电转换效率已经突破 $12 \%{ }^{2}$ 典型的 DSC 由纳米 宽禁带半导体薄膜、光敏染料、电解质和对电极组 成. 尽管作为纳米半导体光阳极的半导体材料有很 多种, 但到目前为止, 光电转换效率最高的仍是纳 米 $\mathrm{TiO}_{2}$. 研究者们对染料敏化太阳电池的结构和工 作原理已进行了详细的研究和论述, ${ }^{3-8}$ 其系统内部 存在着复杂的能量交换过程及多种电荷传输和电 荷转移界面, 包括 $\mathrm{TiO}_{2}$ 薄膜与导电玻璃的接触界 面、 $\mathrm{TiO}_{2}$ /染料/电解质界面和电解质/对电极界面. 其 中光敏染料的吸附以及电子的注入、传输和复合都 发生在 $\mathrm{TiO}_{2} /$ 染料/电解质的界面. 该界面反应的发 生会对电池性能造成很大影响. 纳米 $\mathrm{TiO}_{2}$ 由于其大 的比表面积, 为 $\mathrm{TiO}_{2} /$ 染料/电解质界面提供了足够 多的染料吸附位, 保证了足够的电子注入量. 然而, 大的比表面积会导致染料分子在 $\mathrm{TiO}_{2}$ 薄膜表面的 聚集, 但由于染料本身的结构特点, $\mathrm{TiO}_{2}$ 薄膜表面仍 会存在未被染料吸附的空位形成缺陷, 使得 $\mathrm{TiO}_{2}$ 薄 膜中的电子与电解质中电子受体的复合反应加剧, 造成漏电现象, 从而使电池性能的进一步提高受到 限制. 界面电子复合和染料聚集是电池性能降低的 重要因素, 因此, 通过各种途径修饰改善 $\mathrm{TiO}_{2} /$ 染料/ 电解质界面, 进一步提高 DSC 光电转换效率成为该 领域一个重要的研究热点.

为提高染料敏化太阳电池的性能, 国内外的许 多研究者除了致力于寻找新材料外, 还从不同的引 入途径对 $\mathrm{TiO}_{2}$ /染料/电解质的界面进行修饰, 其中 包括 $\mathrm{TiO}_{2}$ 薄膜电极的改性修饰, ${ }^{9-14}$ 共吸附剂的引入 和多种染料共敏化处理 ${ }^{15-26}$ 以及电解质添加剂的应 用 ${ }^{27-35}$ 等. 尽管对 $\mathrm{TiO}_{2}$ /染料/电解质界面修饰的研究 工作很多, 但对这些修饰手段进行系统全面的评述 则甚少见诸文献报道. ${ }^{36-38}$ 本文结合了本研究组的相 关研究工作, 从界面修饰的不同引入途径对上述方 法进行了总结, 并对其未来发展方向进行了展望.

\section{$2 \mathrm{TiO}_{2}$ 光阳极改性修饰}

纳米 $\mathrm{TiO}_{2}$ 多孔薄膜电极作为染料敏化太阳电 池的关键组成部分之一, 其性能的好坏直接影响电 池的效率及稳定性. $\mathrm{TiO}_{2}$ 薄膜电极由于其高比表面 积产生大量陷阱态, 使得 DSC 暗电流较大. 因此, 人 们采用了多种方法修饰 $\mathrm{TiO}_{2}$ 薄膜电极以抑制内部
复合, 主要包括 $\mathrm{TiO}_{2}$ 薄膜的表面化学改性, ${ }^{39,40}$ 表面 包覆 ${ }^{41-43}$ 和掺杂改性 ${ }^{44-49}$ 等.

\section{1 表面化学改性}

$\mathrm{TiCl}_{4}$ 水溶液、 $\mathrm{TiO}_{2}$ 溶胶处理、电沉积处理和小 分子酸处理等是半导体表面化学改性的主要方法. 这些方法在浸泡染料之前进行, 其中 $\mathrm{TiCl}_{4}$ 水溶液处 理是目前最为常用的光阳极表面修饰方法, 处理后 通常可以提高电池的光电流, 从而使电池的光电性 能得到提高. Grätzel 研究组认为, ${ }^{50-54} \mathrm{TiO}_{2}$ 光阳极表 面经 $\mathrm{TiCl}_{4}$ 溶液处理后, 会在纯度不高的 $\mathrm{TiO}_{2}$ 表面包 裹一层高纯度的 $\mathrm{TiO}_{2}$, 染料吸附量的增加提高了电 子注入效率; 同时, 他们发现经过处理后的 $\mathrm{TiO}_{2}$ 薄 膜, 尽管其比表面积和平均孔径有所下降, 但是纳 米 $\mathrm{TiO}_{2}$ 颗粒间的接触有所改善, 使电子在颗粒间的 传输变的容易, 从而减少了电子复合的可能, 使光 电流有所提高. Sommeling 等 ${ }^{39}$ 对 $\mathrm{TiCl}_{4}$ 处理的作用 提出了另一种解释, 他们认为, 当 $\mathrm{TiO}_{2}$ 薄膜用 $\mathrm{TiCl}_{4}$ 处理后, 其导带位置发生正移, 使原本不能注入 $\mathrm{TiO}_{2}$ 的电子注入, 增加了光电子的注入效率. 笔者研究 组发现, ${ }^{55} \mathrm{TiCl}_{4}$ 处理虽然减少了膜的比表面积, 但增 强了电学接触, 还使得敏化剂 $\mathrm{N} 719$ 与 $\mathrm{TiO}_{2}$ 结合的键 强度增大, 最终得出当 $\mathrm{TiCl}_{4}$ 溶液浓度为 $0.1 \mathrm{~mol} \cdot \mathrm{L}^{-1}$ 时, 电池性能得到最佳改善, 其光电转换效率 $(\eta)$ 提 高了 $25 \% . \mathrm{TiCl}_{4}$ 作为表面化学改性的一种常用手 段, 其修饰效果与纳晶半导体 $\mathrm{TiO}_{2}$ 的微观形貌等有 关, 对不同微结构的纳晶 $\mathrm{TiO}_{2}$, 其处理的优化条件可 能会有所不同.

一维的 $\mathrm{TiO}_{2}$ 纳米结构光阳极由于可以很好地 为电子提供传输路径而得到广泛研究, 56,57 将这类材 料进行 $\mathrm{TiCl}_{4}$ 处理也得到了很好的效果. Song 等 ${ }^{58}$ 将 $\mathrm{TiO}_{2}$ 纳米纤维作为光阳极应用到基于聚合物凝胶电 解质的 $\mathrm{DSC}$ 中, 经过 $\mathrm{TiCl}_{4}$ 水溶液处理后, 在 $\mathrm{TiO}_{2}$ 纤 维的表面形成了一层新的 $\mathrm{TiO}_{2}$ 层, 使染料的吸附量 增加. $\mathrm{Liu}$ 和 $\mathrm{Aydi}^{59}$ 用 $\mathrm{TiCl}_{4}$ 溶液处理 $4 \mu \mathrm{m}$ 长的纳米 棒光阳极, 光电转换效率达到 $3 \%$. Charoensirithavorn 等 ${ }^{60}$ 发现用 $\mathrm{TiCl}_{4}$ 处理 $\mathrm{TiO}_{2}$ 纳米管薄膜, 不 仅提高了染料的吸附量, 还增强了 $\mathrm{TiO}_{2}$ 薄膜内的电 子传输速率, 得到的开路电压 $\left(V_{\mathrm{oc}}\right)$ 和短路电流 $\left(J_{\mathrm{sc}}\right)$ 是 未处理前的 2 倍. Wang 和 $\mathrm{Lin}^{61}$ 将 $\mathrm{TiCl}_{4}$ 处理后的 $\mathrm{TiO}_{2}$ 纳米管薄膜持续暴露在 $\mathrm{O}_{2}$ 等离子体中, 由于 $\mathrm{O}_{2}$ 等离 子体处理改善了 $\mathrm{TiO}_{2}$ 表面的亲水性, 增加了染料的 吸附量, 从而使电池的光电转换性能显著增强, 研 究者利用 $14 \mu \mathrm{m}$ 厚的 $\mathrm{TiO}_{2}$ 纳米管作为光阳极, 经后 
处理的电池光电转换效率达到 $7.37 \%$.

$\mathrm{TiO}_{2}$ 光阳极表面的溶胶处理和电沉积处理也表 现出显著的优势. $\mathrm{Yu}$ 等 ${ }^{62}$ 用钛有机溶胶处理纳米 $\mathrm{TiO}_{2}$ 光阳极, 获得了 $7.3 \%$ 的光电转换效率, 比未处 理的 $\mathrm{TiO}_{2}$ 光阳极电池提高 $28 \%$; 他们认为, 钛有机溶 胶处理有效地改善了 $\mathrm{TiO}_{2}$ 薄膜的网络微结构, 使电 子传输速率得到提高, 同时增大了纳米 $\mathrm{TiO}_{2}$ 颗粒之 间和 $\mathrm{TCO}$ 基底 $/ \mathrm{TiO}_{2}$ 薄膜的结合, 增大了短路电流. 笔者研究组 ${ }^{63}$ 采用表面电沉积处理纳米 $\mathrm{TiO}_{2}$ 薄膜 后, 电池的开路电压、短路电流密度和光电转换效率 都有所提高.

小分子酸处理作为 $\mathrm{TiO}_{2}$ 薄膜表面改性的另一 有效方法也得到广泛的应用和研究. 一般认为酸处 理可以改变 $\mathrm{TiO}_{2}$ 薄膜的表面态并形成缺陷中心, 造 成 $\mathrm{TiO}_{2}$ 薄膜表面质子化, 从而影响 $\mathrm{TiO}_{2}$ 导带边的移 动以及染料分子吸附到 $\mathrm{TiO}_{2}$ 颗粒表面的键合形式 和吸附动力学. Hao 等 ${ }^{9}$ 分别采用盐酸、硫酸、硝酸和 磷酸对 $\mathrm{TiO}_{2}$ 光阳极进行处理, 认为盐酸作为非氧化 性的强酸并不会像硝酸破坏 $\mathrm{TiO}_{2}$ 薄膜表面, 硫酸和 膦酸会与 $\mathrm{TiO}_{2}$ 形成强的键合, 降低了染料吸附量, 因此盐酸对电池的处理效果最佳. 他们研究发现, 经 $0.1 \mathrm{~mol} \cdot \mathrm{L}^{-1}$ 的盐酸处理后, 电池的 $V_{\mathrm{oc}}$ 和填充因子 $(\mathrm{FF})$ 得到增加, 但 $J_{\mathrm{sc}}$ 和染料的吸附量减小. Wang 和 $\mathrm{Lin}^{61}$ 用盐酸处理 $\mathrm{TiO}_{2}$ 薄膜, 发现盐酸处理后 $\mathrm{TiO}_{2}$ 薄 膜表面发生质子化, 增大了薄膜对染料的吸附, 从而 提高了 $J_{\mathrm{sc}}$, 分析认为 $J_{\mathrm{sc}}$ 提高不仅是因为染料吸附量 的增大, 还由于盐酸处理后 $\mathrm{TiO}_{2}$ 薄膜平带电势发生 正移, 有利于注入光生电子, 减少氧化态染料与电子 间的复合. Lee 等 ${ }^{13}$ 为提高染料的吸附量, 在染料敏 化前, 先利用紫外光照射 $\mathrm{TiO}_{2}$ 光阳极, 通过光催化 作用达到清除 $\mathrm{TiO}_{2}$ 表面有机杂质的作用, 再将其浸 泡在盐酸溶液中进行表面质子化处理, 染料的吸附 量得到明显增加, 两次处理后的光电转换效率达到 了 $7.39 \%$. Jung 等 ${ }^{12}$ 将光阳极浸渍在硝酸和盐酸溶液 中进行表面处理, 结果发现硝酸的处理效果优于盐 酸, 使电池的光电转换效率由 $5.4 \%$ 增加到 $6.2 \%$, 硝 酸处理延缓了 $\mathrm{TiO}_{2}$ 薄膜/电解质的电子复合, 同时增 加了染料吸附量, 使光电流增加. 由此可见, 酸处理 效果的差异也体现了阴离子在吸附过程的影响, 这 可能与 $\mathrm{TiO}_{2}$ 纳米晶半导体的网络微结构有关, 并有 待进一步深入研究.

表面化学改性作为一种界面修饰的简便方法, 在 DSC 中获得了广泛应用. 其中 $\mathrm{TiCl}_{4}$ 溶液处理几乎
成为改善 $\mathrm{TiO}_{2}$ 薄膜电学接触的标准方法. 由于 $\mathrm{DSC}$ 敏化染料及电解质体系的不同, 对纳晶半导体微观 形貌及表面化学性质要求不同, 从而 $\mathrm{TiO}_{2}$ 表面化学 改性的优化条件可能会有差异.

\section{2 表面包覆}

表面包覆是 DSC 光阳极表面修饰的一种重要 方法, 该修饰方法使 $\mathrm{TiO}_{2}$ 表面包覆一层宽禁带半导 体或绝缘体材料, 形成所谓的 “核-壳” 结构光阳极. 这种结构的光阳极可以有效抑制光生电子在 $\mathrm{TiO}_{2} /$ 染料/电解质界面处复合, 减小暗电流, 从而达到改 善电池性能的目的. 表面包覆的方法主要包括表面 沉积法、 ${ }^{65}$ 溶胶-凝胶法、 ${ }^{66}$ 浸渍法、 ${ }^{67}$ 磁控溅射法 ${ }^{68}$ 和 原子层沉积法 ${ }^{69}$ 等, 根据制备方法的不同, 表面包覆 后的光阳极可以得到两种不同的结构(如图 1 所示): (a) 先对纳米 $\mathrm{TiO}_{2}$ 颗粒进行包覆处理, 再将得到的 “核-壳”结构纳米粒子制成薄膜光阳极; (b)直接对 烧结好的纳米 $\mathrm{TiO}_{2}$ 薄膜进行处理, 得到“核-壳” 结构 的光阳极. 其中后一种结构在电子传输上表现出明 显的优势。

Zaban 等 ${ }^{70}$ 于 2001 年首次在 $\mathrm{TiO}_{2}$ 表面包覆了一 层 2-3 nm 厚的 $\mathrm{Nb}_{2} \mathrm{O}_{5}$, 这种宽禁带半导体在 $\mathrm{TiO}_{2}$ /电 解质界面形成了一个复合势垒, 注入到光阳极的电 子需要克服这个势垒才可以与电解质中的电子受体 发生复合. 包覆层有效抑制了光生电子的复合, 并使 该电池的光电转换效率与未处理 $\mathrm{TiO}_{2}$ 相比提高了 $35 \%$. 自此, 对光阳极进行表面包覆受到了研究者们 的广泛关注, 而要形成这种势垒, 需要寻找比 “核” 结构的导带边更负的 “壳” 材料. Diamant 等 ${ }^{71,72}$ 研究 了一系列宽禁带半导体和绝缘体氧化物, 如 $\mathrm{Nb}_{2} \mathrm{O}_{5}$ 、 $\mathrm{ZnO} 、 \mathrm{SrTiO}_{3} 、 \mathrm{ZrO}_{2} 、 \mathrm{Al}_{2} \mathrm{O}_{3}$ 和 $\mathrm{SnO}_{2}$ 作为包覆材料处理 $\mathrm{TiO}_{2}$ 光阳极并研究其对电池性能的影响. $\mathrm{Nb}_{2} \mathrm{O}_{5}$ 由于 在 $\mathrm{TiO}_{2}$ 表面形成了一层势垒, 抑制了电子复合, 使

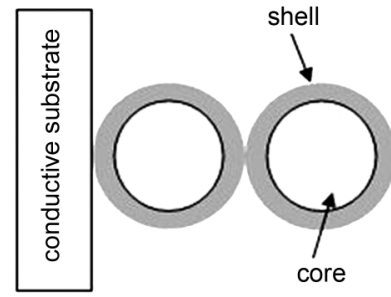

(a)

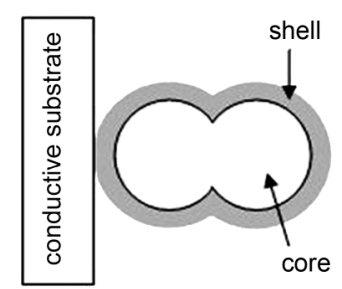

(b)
图 1 不同包覆处理的两种 “核-壳” 结构光阳极示意图 ${ }^{38}$

Fig.1 Schematic representation of core-shell structure electrode coated by two different treatments ${ }^{38}$

(a) The shell layer is formed prior to the film deposition; (b) The shell layer is formed after the film deposition. 
电池的开路电压 $\left(V_{\mathrm{oc}}\right)$ 和短路电流 $\left(J_{\mathrm{sc}}\right)$ 都得到了提高 (图 2). 但其它的包覆材料则表现出了不同的作用机 理. 包覆处理后 $\mathrm{TiO}_{2}$ 的导带边产生移动, $\mathrm{ZnO}$ 、 $\mathrm{SrTiO}_{3} 、 \mathrm{ZrO}_{2}$ 和 $\mathrm{Al}_{2} \mathrm{O}_{3}$ 包覆处理电池的开路电压增 大, 而 $\mathrm{SnO}_{2}$ 却使其减小. 他们认为表面的偶极作用 是产生这种现象的根本原因. 由于 $\mathrm{ZnO} 、 \mathrm{SrTiO}_{3}$ 、 $\mathrm{ZrO}_{2}$ 和 $\mathrm{Al}_{2} \mathrm{O}_{3}$ 的等电点高于 $\mathrm{TiO}_{2}$, 表面偶极层的形成 使 $\mathrm{TiO}_{2}$ 导带边负移, 开路电压提高, 但短路电流相 应减少. 最终得到 $\mathrm{ZnO} 、 \mathrm{SrTiO}_{3}$ 和 $\mathrm{Al}_{2} \mathrm{O}_{3}$ 包覆处理的 电池光电转换效率提高了约 $15 \%$, 用 $\mathrm{ZrO}_{2}$ 包覆处理 的电池光电转换效率减少了近 $11 \%$. 对于 $\mathrm{SnO}_{2}$ 包覆 材料, 由于其等电点比 $\mathrm{TiO}_{2}$ 低, 使电池的开路电压 和短路电流都减小, 导致电池的光电转换效率减少 了约 $45 \%$. Palomares 等 ${ }^{66}$ 对比了三种绝缘体包覆材 料 $\mathrm{SiO}_{2} 、 \mathrm{Al}_{2} \mathrm{O}_{3}$ 和 $\mathrm{ZrO}_{2}$, 它们都可以在 $\mathrm{TiO}_{2}$ /染料/电解 质界面形成一层势垒抑制电子复合的发生, 同时发 现, 由于等电点的不同, $\mathrm{Al}_{2} \mathrm{O}_{3}$ (等电点约为 9.2)表现 出最优性能. 使电池的开路电压提高了 $50 \mathrm{mV}$, 光电 转换效率提高了 $35 \%$. Wu 等 ${ }^{73}$ 采用射频磁控溅射法 制备了 $\mathrm{Al}_{2} \mathrm{O}_{3}$ 包覆的核壳结构薄膜, 认为该薄膜增大 了染料吸附量, 减少了 $\mathrm{TiO}_{2}$ 表面的俘获位点, 同时 抑制了界面电子复合. Jung 等 ${ }^{74}$ 采用溶胶-凝胶法在
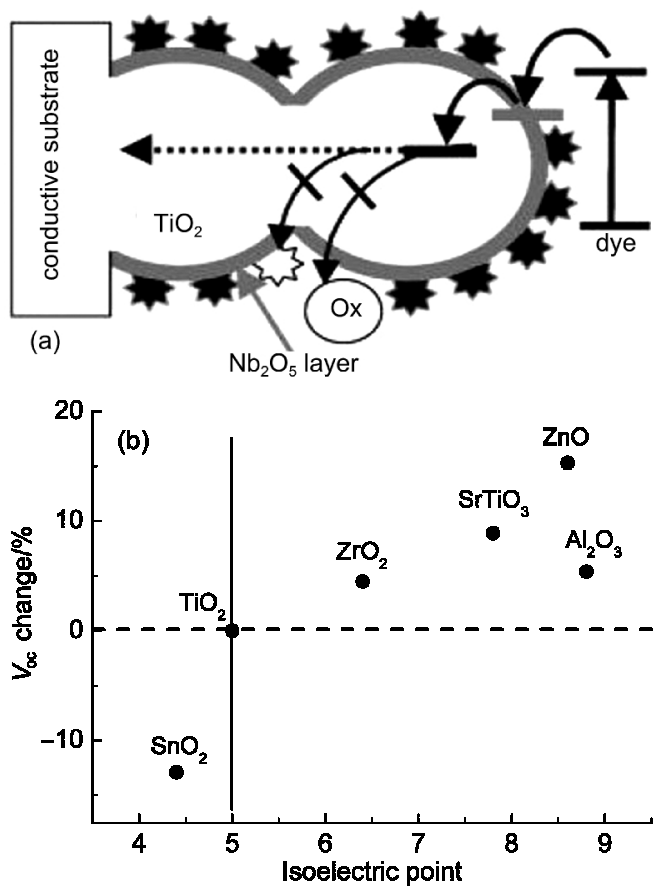

图 2 (a) $\mathrm{Nb}_{2} \mathrm{O}_{5}$ 表面包覆 $\mathrm{TiO}_{2}$ 的核壳结构示意图; ${ }^{71}$ (b) DSC 中基于不同等电点的包覆材料的开路电压 $\left(V_{\mathrm{oc}}\right)$ 差异 ${ }^{72}$

Fig.2 (a) Schematic view of the $\mathrm{Nb}_{2} \mathrm{O}_{5} / \mathrm{TiO}_{2}$ core-shell electrode; ${ }^{71}(\mathrm{~b})$ the dependence of open circuit voltage $\left(V_{\mathrm{oc}}\right)$ on the isoelectric point of the shell material in a $\mathrm{DSC}^{72}$
$\mathrm{TiO}_{2}$ 表面包裹了一层绝缘体材料 $\mathrm{MgO}$, 增大了光阳 极的比表面积, 从而增强了染料的吸附, 使电池的光 电转换效率增大了 $45 \%$. 笔者研究组 ${ }^{75}$ 选择绝缘体 材料 $\mathrm{Y}_{2} \mathrm{O}_{3}$ 作为包覆材料组成 “核-壳” 结构应用在 DSC 中, 发现包覆处理后的薄膜平带电势负移且电 子复合得到有效抑制, 电子寿命增大, 电池的开路电 压明显提高.

此外, $\mathrm{CaCO}_{3}{ }^{76}$ 和 $\mathrm{BaCO}_{3}{ }^{77}$ 等三元化合物绝缘体 材料也被应用在 DSC 中. Park 等 ${ }^{78}$ 采用浸渍法用镁 盐( $\mathrm{MS} ; \mathrm{MgCO}_{3}$ 和 $\left.\mathrm{Mg}\left(\mathrm{CH}_{3} \mathrm{COO}\right)_{2}\right)$ 修饰 $\mathrm{TiO}_{2}$ 光阳极, 形成 $\mathrm{MS}-\mathrm{TiO}_{2}$ 核壳结构应用到 DSC 中, 他们认为, $\mathrm{TiO}_{2}$ 表面染料吸附量的增大使 $J_{\mathrm{sc}}$ 增大了 $10 \%$, 而 $\mathrm{MS}$ 作为光阳极表面的偶极子使 $\mathrm{TiO}_{2}$ 的导带边向负方 向移动, 导致 $V_{\mathrm{oc}}$ 增大了 $6.5 \%$, 最终使电池光电转换 效率获得 $17 \%$ 的提高. $\mathrm{Wu}$ 等 ${ }^{77}$ 将绝缘体材料 $\mathrm{BaCO}_{3}$ 修饰 $\mathrm{TiO}_{2}$ 光阳极应用到准固态 $\mathrm{DSC}$ 中, 在 $30 \mathrm{~mW}$. $\mathrm{cm}^{-2}$ 的光照下, 其光电转换效率由 $5.53 \%$ 提高到 $6.96 \%$.

表面包覆作为光阳极界面修饰的一种方法, 在 过去的十多年中得到了很多关注. 其中包覆材料及 包覆工艺直接决定包覆结果, 目前研究者们已经尝 试了多种包覆材料, 但由于壳层的厚度、晶型及对核 层的覆盖不能得到理想的控制, 因此包覆处理对 DSC 的性能影响仍存在很多不确定性.

\section{3 掺杂改性}

相对于上述针对纳米 $\mathrm{TiO}_{2}$ 半导体薄膜本体的 表面修饰, $\mathrm{TiO}_{2}$ 半导体薄膜的掺杂改性, 可以调控其 内部的能带结构, 影响其电极性能, 进而会对 DSC 中染料的吸附及 $\mathrm{TiO}_{2}$ /染料/电解质界面性质造成影 响. $\mathrm{TiO}_{2}$ 光阳极掺杂主要包括非金属掺杂 ${ }^{44-47}$ 和金属 特别是稀土离子掺杂 $45,79-83$ 等.

非金属掺杂主要采用 $N 、 B 、 S$ 等主族元素对 $\mathrm{TiO}_{2}$ 光阳极进行掺杂. $\mathrm{Ma}$ 等 ${ }^{44}$ 采用氮掺杂的纳米 $\mathrm{TiO}_{2}$ 粉末制备 $\mathrm{DSC} \mathrm{TiO}_{2}$ 光阳极. 研究发现 $\mathrm{N}$ 掺杂拓 展了 $\mathrm{DSC}$ 中 $\mathrm{TiO}_{2}$ 光阳极的光响应范围, 基于 $\mathrm{N}$ 掺杂 $\mathrm{TiO}_{2}$ 光阳极的 DSC 经过 $2000 \mathrm{~h}$ 的紫外老化处理, 表 现出优异的稳定性. 笔者研究组 ${ }^{45-47}$ 利用溶胶-凝胶 法制备了 $\mathrm{N}$ 掺杂 $\mathrm{TiO}_{2}$ 半导体薄膜, 发现掺杂的 $\mathrm{N}$ 能 够部分代替 $\mathrm{TiO}_{2}$ 晶格中的氧缺陷, 使得 $\mathrm{TiO}_{2}$ 薄膜的 平带电势负移, 电池的开路电压升高; $\mathrm{N}$ 掺杂增大了 $\mathrm{DSC}$ 中的电子寿命, 降低了 $\mathrm{TiO}_{2} /$ 染料/电解质界面 的电子复合, 提高了 DSC 的光热稳定性. 笔者研究 组制备了高结晶度嗍掺杂 $\mathrm{TiO}_{2}$ 半导体薄膜应用到 
DSC 中, 相对于未掺杂的器件, 其短路电流得到较 大的提高, 入射单色光光电转换效率(IPCE)值在 370 $-650 \mathrm{~nm}$ 之间有明显的提高. 利用共掺杂原子或离 子的协同效应, 综合 $\mathrm{N}$ 掺杂和 $\mathrm{B}$ 掺杂的优缺点, 我们 又进一步研究了 $\mathrm{N} 、 \mathrm{~B}$ 共掺杂纳米 $\mathrm{TiO}_{2}$ 颗粒, 通过 $\mathrm{N}$ 、 $\mathrm{B}$ 共掺杂能有效调控 $\mathrm{TiO}_{2}$ 的能带结构. 同时, 适量的 $\mathrm{N} 、 \mathrm{~B}$ 共掺杂能够有效提高 DSC 的光伏性能和电池 的长期稳定性, 有效抑制 $\mathrm{TiO}_{2} /$ 染料/电解质界面的 电子复合反应, 延长电子寿命.

金属掺杂也是提高 $\mathrm{TiO}_{2}$ 光阳极性能的一种有 效途径. Zhang 等 ${ }^{45}$ 用溶胶-凝胶法合成了铇 $(\mathrm{W})$ 掺杂 $\mathrm{TiO}_{2}$ 光阳极, 调控 $\mathrm{W}$ 的掺杂量从 $0.1 \%$ 增加到 $5 \%$, $\mathrm{TiO}_{2}$ 导带边正移, 提高了 $\mathrm{DSC}$ 的短路电流, 同时, $\mathrm{W}$ 掺杂的 $\mathrm{TiO}_{2}$ 有效抑制了电子复合, 提高了电子寿命. Alarcón等 79 用电化学的方法将 $\mathrm{Al}^{3+}$ 掺杂进 $\mathrm{TiO}_{2}$ 薄膜 电极后, 其电子寿命和电子传输时间都有所增大. $\mathrm{Lin}$ 与其合作者 ${ }^{82,84-86}$ 采用水热法在 $\mathrm{TiO}_{2}$ 光阳极掺杂 了金属元素铝 $(\mathrm{Al}) 、$ 钽 $(\mathrm{Ta}) 、$ 锑 $(\mathrm{Sb})$, 同样提高了 $J_{\mathrm{sc}}$, 并对电子复合起到抑制作用. 这部分研究工作主要 是通过提高电子注入效率来提高光电流, 但 $\mathrm{TiO}_{2}$ 导 带边的正移却使 DSC 的开路电压有所降低. 后来, 他们同样采用水热法在 $\mathrm{TiO}_{2}$ 薄膜中掺入了不同浓 度的锡( $\mathrm{Sn}$ ), 发现电子在掺杂膜内的传输速率增大 不仅使 $J_{\mathrm{sc}}$ 明显提高, $\mathrm{Sn}$ 的掺入还会导致 $\mathrm{TiO}_{2}$ 平带电 势的负移, 提高了 $V_{\mathrm{oc}}$, 最终使电池的光电转换效率 提高了 $12.1 \%$. 笔者研究组 ${ }^{81}$ 将金属离子 $\mathrm{Mg}^{2+}$ 掺进 $\mathrm{TiO}_{2}$ 晶格中, 研究了 $\mathrm{Mg}^{2+}$ 掺杂对 $\mathrm{TiO}_{2}$ 半导体带边移 动及器件电子复合的影响, 发现 $\mathrm{Mg}^{2+}$ 掺杂的 $\mathrm{TiO}_{2}$ 薄 膜电极与未掺杂的相比, 导带边负移了 $70 \mathrm{mV}$, 在相 同的光电子密度下提高了电子扩散系数. 但是, 掺杂 处理增加了 $\mathrm{TiO}_{2}$ 光阳极的表面缺陷态, 降低了电子 寿命, 加快了复合速率, 两种作用的最终结果使 DSC 的开路电压提高了 $15 \mathrm{mV}$. 稀土元素易产生多 电子组态, 并且热稳定性好, 广泛应用于半导体的掺 杂改性上. 杨术明等 ${ }^{87}$ 研究了 $\mathrm{Yb}^{3+}$ 等 13 种稀土离子 掺杂对 $\mathrm{TiO}_{2}$ 薄膜电极的影响, 其中 $\mathrm{Yb}^{3+}$ 离子掺杂的 $\mathrm{TiO}_{2}$ 薄膜电极在 $73.1 \mathrm{mV} \cdot \mathrm{cm}^{-2}$ 的白光照射下, DSC 的光电转换效率增大了 $15 \%$. 研究发现, 稀土离子掺 杂以后在 $\mathrm{TiO}_{2}$ 电极表面形成了一个能量势垒, 有效 地抑制了电极表面的复合, 降低了暗电流使得 DSC 的效率提高. 笔者研究组 ${ }^{88}$ 将 $\mathrm{Yb}^{3+}$ 掺杂进 $\mathrm{TiO}_{2}$ 电极, 结果发现 $\mathrm{Yb}_{2} \mathrm{O}_{3}$ 的掺入导致 $\mathrm{TiO}_{2}$ 发生晶格畸变, 减 少了染料吸附量, 从而使短路电流密度相应减小. 但
掺杂后 DSC 开路电压 $V_{\mathrm{oc}}$ 和填充因子 $\mathrm{FF}$ 都相应增 大. 开路电压升高, 说明绝缘体阻挡层的存在使电子 在膜内的填充水平提高, 费米能级负向移动, 与电解 质氧化还原电位之间的距离拉大. $\mathrm{Yb}$ 元素部分以 $\mathrm{Yb}_{2} \mathrm{O}_{3}$ 的形式存在形成表面势垒, 起到抑制暗电流 的作用.

掺杂处理作为 $\mathrm{TiO}_{2}$ 光阳极改性处理的有效手 段得到了广泛的研究, 通过有选择性的掺杂能有效 地抑制 DSC 界面电子的复合, 同时不同元素的掺杂 会影响 $\mathrm{TiO}_{2}$ 能带结构, 部分元素的掺杂还能提高 DSC 的稳定性, 但是目前掺杂工艺的优化、掺杂量 的精确控制以及掺杂处理对 DSC 界面动力学的影 响等工作还需要进一步深入研究.

$\mathrm{TiO}_{2}$ 光阳极是 $\mathrm{DSC}$ 的重要组件, 在染料敏化前 对其进行修饰改性在过去的二十年中已经取得快速 发展. 目前, 研究者们仍然在寻求更简单更有效的修 饰方法, 并通过多种手段共同处理 ${ }^{89} \mathrm{TiO}_{2}$ 薄膜来优 化 DSC 的性能. 但是, 对于这些修饰方法的作用机 理仍然存在争议, 该方向的研究在科学与技术上仍 然具有很大的挑战性.

\section{3 染料溶液中共吸附剂的引入及多染料共 敏化处理}

为了提高染料敏化太阳电池的光电转换效率, 研究者从染料溶液入手, 一方面引入共吸附剂有机 小分子对界面进行修饰, 另一方面采用多种染料共 敏化处理 $\mathrm{TiO}_{2}$ 薄膜, 从不同的角度提高电池的光电 转换性能.

\section{1 共吸附剂对界面修饰的作用}

与染料分子类似, 作为共吸附剂的有机小分子 拥有吸附基团, 和染料共同作用在二氧化钛表面上. 共吸附剂分子可以填补未被染料吸附的空位而吸附 在 $\mathrm{TiO}_{2}$ 上, 其作用主要表现为抑制染料在 $\mathrm{TiO}_{2}$ 薄膜 表面的聚集, 提高电子注入效率; 与染料共同形成 一层紧密的单分子层, 抑制电解质中电子受体与 $\mathrm{TiO}_{2}$ 导带中的电子或激发态染料的电子复合反应, 从而提高电池的光电转换效率. ${ }^{90}$

1993 年, Kay 和 Grätzel ${ }^{15}$ 首次将共吸附剂分子 引入 DSC 中, 研究了一系列共吸附剂对电池各性能 参数的影响, 发现胆酸类有机小分子表现出优越的 共吸附性能. 随后, 胆酸衍生物做为共吸附剂在 DSC 中得到广泛的应用和研究. 目前常用的胆酸衍 生物主要为脱氧胆酸(DCA, 结构见图 3)和我脱氧胆 
酸(CDCA, 结构见图 3), 对其修饰机理也做了深入 的探讨. $\mathrm{Li}$ 等 ${ }^{91}$ 将 $\mathrm{CDCA}$ 作为共吸附剂引入以吩噻 嗪类染料为敏化剂的 DSC 中. 发现 CDCA 可以有效 抑制染料的聚集, 提高了电子注入效率和 $J_{\mathrm{sc}}$. 同时, 由于 CDCA 抑制了电子复合, 提高了电子寿命, 使 $V_{\mathrm{oc}}$ 也有了一定程度的提高. 与不加 CDCA 的染料溶 液相比, 基于此有机染料的电池效率获得了明显提 升. Sharma 等 ${ }^{92}$ 在以二菘嵌苯类染料为敏化剂的 DSC 中引入 $\mathrm{DCA}$, 其结果表明 DCA 与 CDCA 的作用类 似, DCA 的加入同时使电池的短路电流和开路电压 得到提高, 与未使用 DCA 的电池相比, 其光电转换 效率由 $3.07 \%$ 提高到 $4.48 \%$.

Wang 等 ${ }^{16}$ 尝试用十六烷基丙二酸分子(HDMA, 结构见图 3) 作为共吸附剂进行了研究. 该酸通过分 子一端的两个羧基与 $\mathrm{TiO}_{2}$ 表面的 $3 d$ 轨道结合. 当 HDMA 和两亲性染料 Z907 进行共吸附时, 能够提 高 DSC 的光电转换性能, 取得了 $7.8 \%$ 的光电转换效 率. 而后, 他们 ${ }^{18}$ 在基于二元离子液体电解质的 Z907 敏化太阳电池中引入了共吸附剂 3-苯基丙酸(PPA, 结构见图 3), 获得 7\%的光电转换效率, 电池的 $J_{\mathrm{sc}}$ 显 著增加. Zhang 等 ${ }^{93}$ 比较了一类新型的共吸附分子 4胍基丁酸盐酸盐(GBA, 结构见图 3), 同时将其与胍 基乙酸盐酸盐(GAA, 结构见图 3)、6-胍基己酸盐酸 盐(GHA, 结构见图 3)等几种胍基衍生物进行了比较 研究. 研究发现胍基盐分子与 Z907 共吸附时, 在共

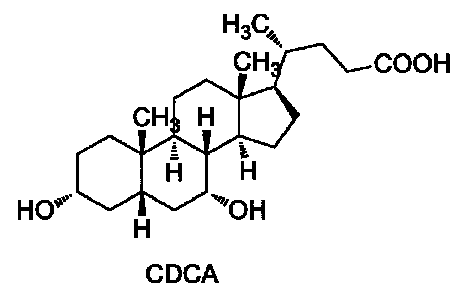

吸附剂比例合适的情况下, 能够提高 DSC 的开路电 压而不减少电池的短路电流, 使器件光电转换效率 提高了 $15 \%$. GBA 分子在提高半导体导带边缘的同 时, 还能够抑制 $\mathrm{TiO}_{2}$ 导带中电子与电解液中 $\mathrm{I}_{3}^{-}$的复 合. 该分子首次被发现具备以上这两种效果. 2009 年, $\mathrm{Li}$ 等 ${ }^{94}$ 将新戊酸(PVA, 结构见图 3)作为共吸附剂 应用到以 Z907Na 为敏化剂的 DSC 中, 发现 PVA 同 样起到了改善电池性能的作用, 先对光阳极进行共 吸附剂处理然后再吸附染料的方式表现出了更好的 性能, 使电池效率提高了 $8 \% .2012$ 年, Kwon 等 ${ }^{95}$ 合 成一种新型的树枝状共吸附剂分子 3,4,5-三(十二 烷氧基)苯甲酸(DOBA, 结构见图 3)并将其应用在 以 Z907 为敏化剂的固态染料敏化太阳能电池中. DOBA 含有三个长链的烷氧基, 可以与染料形成致 密的混合单分子层, 这三个疏水链有效阻止了 $\mathrm{TiO}_{2}$ 导带电子与固态电解质中空穴的复合, DOBA 的 引入避免了电子复合引起的 $51 \%$ 的电流损失. 此 外, $\mathrm{DOBA}$ 使 $\mathrm{TiO}_{2}$ 导带边的负移, 从而提高器件开路 电压.

在酸性基团中膦酸与金属氧化物表面的结合强 度最强, 其次是羧酸及其衍生物. ${ }^{96}$ 在 DSC 的应用 中, 与 $\mathrm{TiO}_{2}$ 有更强的结合能力就意味着有更好的稳 定性和耐久性. 因此, 近年来也出现了许多膦酸基类 共吸附剂分子的合成和研究. Wang 等 ${ }^{17}$ 采用癸基膦 酸(DPA, 结构见图 4)作为共吸附, 研究了其对基于

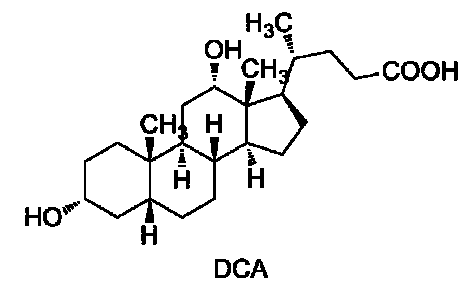

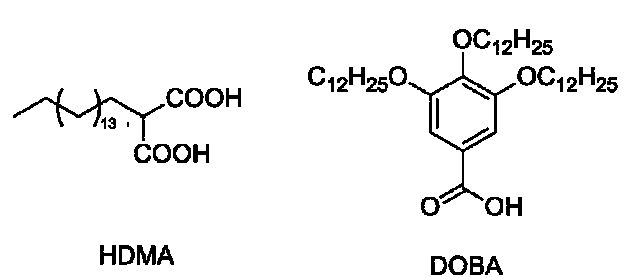<smiles>[N-]=[N+]=C(N)NCCCC(=O)O</smiles>

GBA<smiles>CC(C)(C)C(=O)O</smiles>

pivalic acid<smiles>O=C(O)CCc1ccccc1</smiles>

PPA<smiles></smiles>

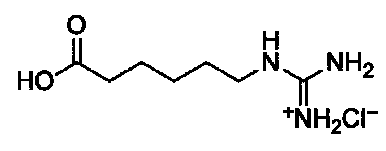

GHA

图 3 脱氧胆酸(DCA), 我脱氧胆酸(CDCA)和几种链状羧酸及其衍生物共吸附剂分子的结构示意图

Fig.3 Scheme of molecular structures of deoxycholic acid (DCA), chendeoxycholic acid (CDCA) and several long-chain carboxylic acid derivative coadsorbents 


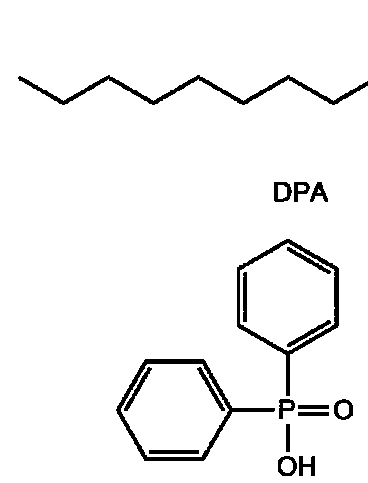

DPPA

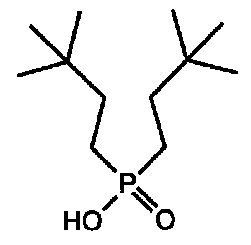

DINHOP

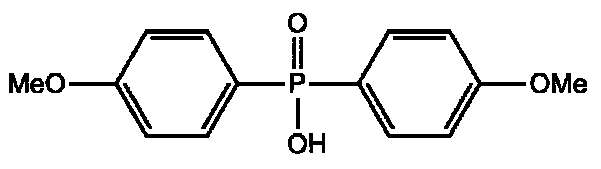

BMPPA

图 4 膦酸类共吸附剂分子的结构示意图

Fig.4 Scheme of molecular structures of phosphonic acid coadsorbents

Z907 染料 DSC 光电性能和耐久性的影响. DPA 的掺 入明显提高了电池的 $J_{\mathrm{sc}}$, 但对 $V_{\mathrm{oc}}$ 和 FF 的影响较小. Allegrucci 等 ${ }^{23}$ 在基于卟啉的染料敏化太阳电池中 引入了共吸附剂双(4-甲氧基苯基)次膦酸(BMPPA, 结构见图 4), 将敏化后的光阳极用 BMPPA 进行不同 时间的处理, 并采用不同组分的电解质进行对比, 发 现无论电解质中的添加剂存在与否, BMPPA 对电 池的 $J_{\mathrm{sc}}$ 都有不同程度的提高. Wang 等 ${ }^{97}$ 合成了一 种含有两条疏水烷基链次膦酸二新已基次膦酸 (DINHOP, 结构见图 4), 将其与 Z907Na 进行共吸附, 当染料与共吸附剂的摩尔比为 $1: 1$ 时, 光电转换效 率由 $7.2 \%$ 提高到 $7.9 \%$. DINHOP 有效抑制了电子复 合使 $\mathrm{TiO}_{2}$ 导带负移, 同时促进了该电池的长期稳定 性. 林红与其合作者 ${ }^{98-100}$ 对膦酸类共吸附剂也做了 较系统的研究, 该研究组在以 N719 为敏化剂的 DSC 中引入共吸附剂二苯基次膦酸(DPPA, 结构见 图 4), 尽管 DPPA 使染料的吸附量减少, 但 $J_{\mathrm{sc}}$ 仍有所 增加. 另外, 不同比例共吸附剂量的引入使 $\mathrm{TiO}_{2}$ 导 带的移动方向不同. 当 N719:DPPA 的摩尔比为 2:1 和 1:1 时, $\mathrm{TiO}_{2}$ 导带向正向移动, 而当摩尔比增加到 $4: 1$ 时, 其导带边向负方向移动.

最近, 文献中也有其它种类新型结构的共吸附 的相关报导. Song 等 ${ }^{101}$ 合成了一种 Y-型结构的基于 咔唑的共吸附剂分子 HC-A(结构见图 5), 该分子不 仅可以抑制香豆素染料 NKX2677 的 $\pi-\pi$ 聚集, 抑制 电子复合, 提高开路电压, 而且由于其可以吸收一部 分紫外-可见光, 增大了短路电流密度 $J_{\mathrm{sc}}$, 最终使基 于 NKX2677/HC-A 的 DSC 光电转换效率由 $6.68 \%$ 提高到 $8.89 \%$. Han 等 ${ }^{102}$ 合成了一种新型的供体-受 体(Doner-Accepter, D-A)型有机小分子共吸附剂Y-1
和 Y-2(结构见图 5), 在以黑染料为敏化剂的 DSC 中, 其作用不仅表现在抑制染料的聚集和电子复合, 同时可以补偿电解质中 $\mathrm{I}_{3}^{-}$对 $430 \mathrm{~nm}$ 处可见光的吸 收, 使电池的 $J_{\mathrm{sc}}$ 和 $V_{\mathrm{oc}}$ 同时得到提高.

不同的染料由于其本身的结构差异, 有些分子 的聚集程度比较大, 共吸附剂对聚集的抑制作用比 较明显, 有助于提高电子的注入效率使短路电流增 大. ${ }^{103}$ 有些染料则在 $\mathrm{TiO}_{2}$ 表面上不易发生聚集, 引入 共吸附剂后, 可能会导致染料在 $\mathrm{TiO}_{2}$ 表面的覆盖量 大量减少, 对电池性能的提高造成不利影响. ${ }^{104}$ 对于 大多数有机染料, 常使用胆酸类衍生物作为共吸附 剂分子 ${ }^{105,106}$ 以达到抑制染料聚集提高电子注入效率 的目的. 而对于两亲性钉染料(例如 Z907)则常选择 同样具有两亲性的链状羧酸或膦酸及其衍生物作为 共吸附剂, 这样可以在 $\mathrm{TiO}_{2}$ 表面形成致密的混合单

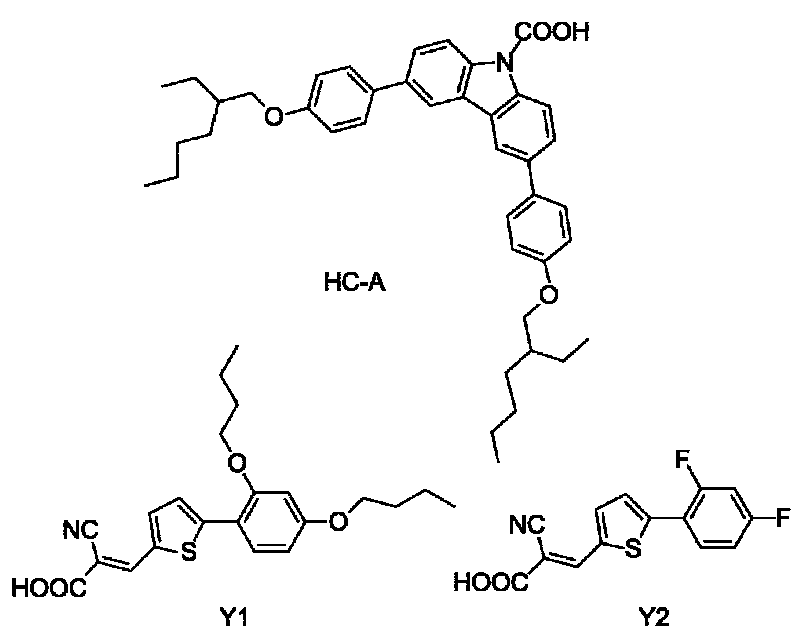

图 5 共吸附剂分子 HC-A、Y1 和 $Y 2$ 的结构示意图

Fig.5 Scheme of molecular structures of coadsorbents HC-A, Y1, and Y2 
分子层, 有效抑制电子的复合同时提高电池稳定性. 因此, 不同染料敏化的电池体系, 在选择共吸附剂时 要根据染料分子的结构特点来对电池的界面进行修 饰. 目前共吸附剂的种类在不断增多, 新型的 D-A 型共吸附剂不仅具有界面修饰的作用, 还可以吸收 一部分可见光, 对电池短路电流的提高具有一定的 促进作用, 成为共吸附剂发展的新方向.

\section{2 多种染料共敏化处理}

单一染料对 $\mathrm{TiO}_{2}$ 薄膜的敏化由于其吸收光谱 的限制, 不能充分利用太阳的发射光谱. 为此研究者 们采用共敏化方法, 将光谱响应具有互补性质的两 种或多种染料配合使用, 拓宽了吸收光谱以增大光 的收集效率. ${ }^{26,107-111} \mathrm{Kuang}$ 等 ${ }^{107}$ 选择两种具有不同吸 收波长的染料, JK-2 ( $\left.\lambda_{\text {max }}=452 \mathrm{~nm}\right)$ 和 SQ-1 ( $\lambda_{\text {max }}=636$ $\mathrm{nm}$ ), 对 $\mathrm{TiO}_{2}$ 光阳极进行共敏化处理, 将 $\mathrm{TiO}_{2}$ 薄膜在 SQ-1 染料溶液中浸泡 $4 \mathrm{~h}$ 后再在 JK-2 溶液中浸泡 2 $\mathrm{h}$, 在基于二元离子液体电解质的电池中得到了最佳 光电转换效率, 并显著高于两种染料分别敏化的电 池效率. 张宝文与其合作者 ${ }^{112-115}$ 合成了系列基于烷 基苯胺的有机染料, 并对共敏化处理 $\mathrm{TiO}_{2}$ 薄膜电极 做了系统研究, 他们采用三种吸收光谱互补的染料 (苯胺类、半菁类和方酸类)进行共敏化, 使电池的光 电转换效率达到了 $6.5 \%$. 为了提高光电压, 研究者 在选择光谱互补的染料时, 更希望可以对界面处的 电子复合进行抑制, 提高电子寿命, 进一步优化电池 性能. Nguyen 等 ${ }^{116}$ 选择光谱可以互补且分子大小不 同的的钓染料 C106 和有机染料 D131 共敏化处理 $\mathrm{TiO}_{2}$ 薄膜, 不仅得到了高的光收集效率, 同时还对 $\mathrm{TiO}_{2}$ 表面起到针化作用. 共敏化后的电池光电转换 效率达到了 $11.1 \%$, 显著高于两种染料单独敏化的 电池效率(D131, $\eta=5.6 \% ; \mathrm{C} 106, \eta=9.5 \%)$. 研究者认 为, 两种染料吸收光谱的互补提高了短路电流, 其分
子大小的不同使得 $\mathrm{TiO}_{2}$ 薄膜表面得到更好的覆盖, 抑制了电子复合并提高了电子寿命, 从而提高了开 路电压(如图6 所示).

多种染料协同敏化作为提高 DSC 性能的一条 途径一直以来都受到研究者们的关注, 而在选取协 同敏化的染料分子时, 不仅考虑到吸收光谱的互补 性质, 对于 $\mathrm{TiO}_{2} /$ 染料/电解质界面的修饰上, 更希望 可以抑制电子复合, 使短路电流和开路电压都得到 提高, 进而提高整个电池的效率, 这将成为 DSC 共 敏化研究的一个新发展方向.

综上所述, 从染料溶液着手, 不管是选择共吸附 剂还是多种染料协同敏化, 很多对 $\mathrm{TiO}_{2} /$ 染料/电解质 界面修饰的微观作用机理还不够完善, 该方向的研 究对于进一步优化电池性能具有一定的积极意义.

\section{4 电解质添加剂对界面修饰的作用}

电解质是染料敏化太阳电池的重要组成部分之 一, 主要分为液体电解质(包含基于有机溶剂的和基 于离子液体的两类)、准固态电解质和固态电解质三 种类型. 液体电解质和准固态电解质中都含有氧化 还原电对、溶剂、有机和无机添加剂. 其中添加剂可 以吸附在 $\mathrm{TiO}_{2}$ 表面, 抑制 $\mathrm{TiO}_{2}$ 光阳极上电子与 $\mathrm{I}_{3}^{-}$之 间电子复合反应的发生, 提高电池的开路电压及电 池效率, 对 $\mathrm{TiO}_{2}$ /染料/电解质界面具有一定的修饰 作用。

电解质添加剂主要是一些含氮杂环化合物, 其 中 4-叔丁基吡啶(TBP) 是电解质中应用最普遍的添 加剂. 1993 年, Grätzel 等 ${ }^{54}$ 首次将 TBP 作为添加剂应 用在 DSC 的界面修饰中, 使电池的开路电压得到了 明显的提高. 随后, 人们对其主要的作用机理做了深 入的研究. TBP 分子可以通过 Ti-N 化学吸附在纳米 $\mathrm{TiO}_{2}$ 的表面从而使其钝化, 影响其电化学性能.

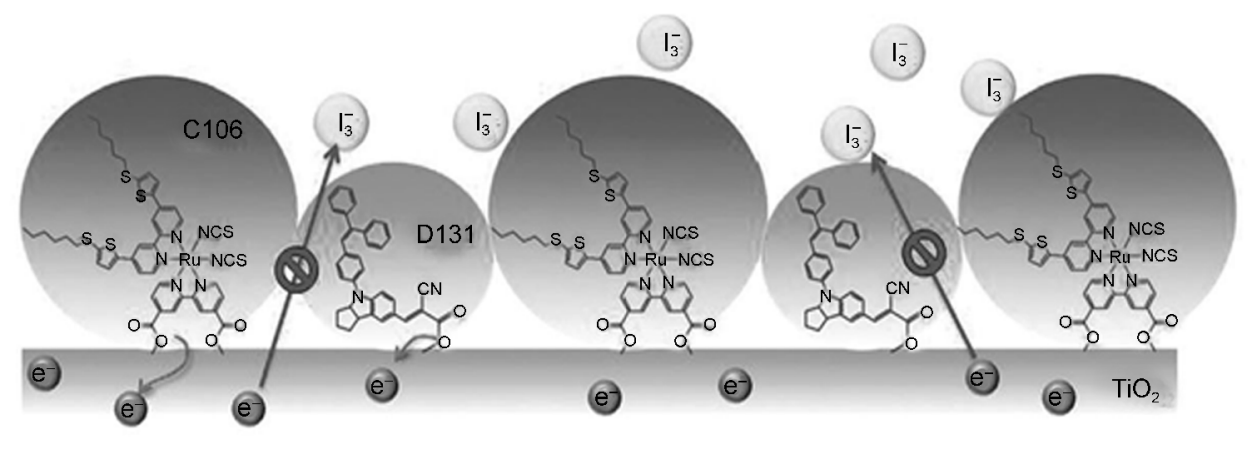

图 $6 \mathrm{C106}$ 和 D131 的结构及其在 $\mathrm{TiO}_{2}$ 表面的吸附位点 ${ }^{116}$

Fig.6 Schematic illustrating molecular structures and adsorption sites of $\mathrm{C106}$ and D131 dyes on $\mathrm{TiO}_{2}{ }^{116}$ 
Huang 等 ${ }^{117}$ 研究发现, TBP 及其衍生物的加入使电 子复合速率减少了 1-2 个数量级. Boschloo 等 ${ }^{118}$ 认 为, 电解质中 $\mathrm{TBP}$ 的引入使 $\mathrm{TiO}_{2}$ 导带负移, 开路电 压 $V_{\mathrm{oc}}$ 提高, 同时界面复合的抑制作用使导带中的电 子寿命提高. TBP 除了能与 $\mathrm{TiO}_{2}$ 相互作用, 还能够通 过和染料分子之间的相互作用影响 DSC 的光电转 换效率, 这种影响也与染料本身的性质有关. 对于常 用的联吡啶钓染料分子会跟随有 $-\mathrm{SCN}$ 作为配体, $\mathrm{TBP}$ 可以阻止染料分子中的 $-\mathrm{SCN}$ 基团损失, ${ }^{119,120}$ 然而, 对于某些对碱较为敏感的有机染料, 通常使用 较低浓度甚至不使用 TBP 作为电解质添加剂. ${ }^{121-123}$ 其它的烷基吡啶及其衍生物、烷基氨基吡啶及其衍 生物作为电解质中的添加剂, ${ }^{28,29}$ 表现出了和 TBP 类 似的效果. Yin 等 ${ }^{124,125}$ 合成了 2-甲基-4-丙氧基吡啶、 2-甲基-4-乙氧基吡啶作为电解质添加剂, 它们都使 $V_{\mathrm{oc}}$ 明显增大, 但 $J_{\mathrm{sc}}$ 略有减少. 其它种常见的含氮杂 环类添加剂还包括 $N$-甲基苯并咪唑(NMBI)、 ${ }^{126-128}$ $N$-丁基苯并咪唑 (NBB)、、落并咪唑 $(\mathrm{BI})^{130,131}$ 等. Kusama 等 ${ }^{132,133}$ 笁选了 20 多种苯并咪唑类衍生物作 为液体电解质中的添加剂, 结果表明, 它们与 TBP 有相同的作用机理. 不同电子供体的含氮杂环包括 氨基三唑、氨基噻唑、嘧啶、咔唑和喹啉等, 不同电子 供体对 $\mathrm{TiO}_{2}$ 光阳极与电解质中 $\mathrm{I}^{-} / \mathrm{I}_{3}{ }^{-}$的相互作用的影 响取决于添加分子的结构特点, 分子轨道计算的结 果表明, $J_{\mathrm{sc}}$ 的下降与分子的偶极矩密切相关, 而 $V_{\mathrm{oc}}$ 的增大与其尺寸和电离能相关.

与含氮杂环类电解质添加剂相比, 另一种电解 质添加剂含有特殊的阳离子. 带正电的阳离子会导 致 $\mathrm{TiO}_{2}$ 导带正移, 使从染料激发态到 $\mathrm{TiO}_{2}$ 导带的电 子注入效率增加, 有利于 $J_{\mathrm{sc}}$ 的提高, 但会使 $V_{\mathrm{oc}}$ 降 低. ${ }^{30,134} \mathrm{DSC}$ 电解质溶液中常用的阳离子添加剂是锂 盐. Kopidakis 等 ${ }^{135}$ 研究认为, $\mathrm{Li}^{+}$可以嵌入 $\mathrm{TiO}_{2}$ 晶格, 对电子的复合以及电子传输性能有很大的影响. 当 电解质中 $\mathrm{Li}^{+}$的浓度增大时, 相应的电子扩散和复合 速率就会减少. 另一常用的阳离子添加剂硫氧酸胍 $(\mathrm{GuSCN})$ 不仅会使 $\mathrm{TiO}_{2}$ 的导带正向移动, ${ }^{20}$ 同时还可 以与染料共同吸附在 $\mathrm{TiO}_{2}$ 表面形成致密的阻挡层, 抑制了电子复合. ${ }^{120}$ 笔者研究组 ${ }^{33}$ 发现, 胍盐正离子化 学吸附到 $\mathrm{TiO}_{2}$ 表面, 使 $\mathrm{TiO}_{2}$ 的平带电势向正方向移 动, 增大了电子注入效率, 从而使短路电流明显增大.

上述两种添加剂对电池 $V_{\mathrm{oc}}$ 和 $J_{\mathrm{sc}}$ 的作用相反, 因 此目前的电解质配方会将两种添加剂结合起来, 通 过调整所用电池体系的电解质配比, 以达到对电池
性能的最佳优化. ${ }^{136,137}$

近年来越来越多的新结构新功能的添加剂材料 被报道出来. Liu等 ${ }^{138}$ 制备了一种基于 3-甲氧基丙腈 的有机电解质, 通过乙酰丙酮、吡啶和碘的季铵化反 应形成两种吡啶碘盐, 与传统的含有 LiI 和 1-甲基3-丙基咪唑碘(MPII)的电解质相比表现出更优异的 性能. Shi 等 ${ }^{139}$ 将冠醚和穴醚引入电解质体系中, 发 现电池的短路电流密度有了一定程度提高. Raja 等 ${ }^{140}$ 合成了一种分子结构呈树枝状的三唑类衍生物 作为添加剂, 这种分子以间苯二甲酸二甲酯为端位, 由于其结构中富含氮原子和氧原子, 因此吸附在 $\mathrm{TiO}_{2}$ 表面提高了开路电压 $V_{\mathrm{oc}}$, 同时与电解质中的 $\mathrm{I}_{2}$ 形成电荷转移复合物抑制了 $\mathrm{I}_{2}$ 的挥发, 增强电池的 稳定性. 笔者研究组 ${ }^{141}$ 将磷酸三丁酯 (TBpp) 作为电 解质添加剂, 由于磷酸酯在 $\mathrm{TiO}_{2}$ 薄膜表面的特殊吸 附方式, 其修饰 $\mathrm{TiO}_{2} /$ 染料/电解质界面显著提高了 电池性能. $\mathrm{TBpp}$ 在 $\mathrm{TiO}_{2}$ 表面分裂为几个部分, 吸附 在 $\mathrm{TiO}_{2}$ 表面形成绝缘层, 有效抑制了电子复合和染 料聚集(如图 7 所示), 其分子本身含有的富电子的烷 氧基作为电子给体使 $\mathrm{TiO}_{2}$ 导带负移, 增大了开路电 压 $V_{\mathrm{oc}}$, 最终使电池的 $\eta$ 提高了 $40 \%$.

离子液体作为一种低温熔融盐几乎没有蒸汽 压, 并且具有较好的稳定性, 作为 DSC 电解质溶剂 能有效防止电解质的挥发和泄露, 但对于常用的挥 发性添加剂仍然会对电池的长期稳定性造成影响. $\mathrm{Kim}$ 等 ${ }^{34}$ 引入了硫脲作为离子液体电解质添加剂使 电池的短路电流 $J_{\mathrm{sc}}$ 得到提高, 而 $V_{\mathrm{oc}}$ 略有减少. 硫艮 的加入使电解质酸性增加, $\mathrm{H}^{+}$浓度增加使 $\mathrm{TiO}_{2}$ 的导 带正移, 导致开路电压降低. 但硫腿与电解质中的 $\mathrm{I}_{2}$

图 7

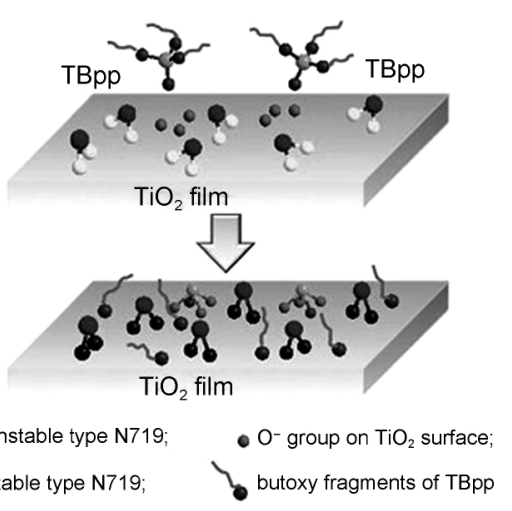

磷酸三丁酯(TBpp)分子和 $\mathrm{N} 719$ 染料在 $\mathrm{TiO}_{2}$ 薄膜 表面相互作用的吸附过程 ${ }^{141}$

Fig7 Process of interaction between the molecular cleavage of tributyl phosphate (TBpp) and the adsorption of $\mathrm{N}_{719}$ on $\mathrm{TiO}_{2}$ film surface ${ }^{141}$ 
反应导致 $\mathrm{I}_{3}{ }^{-}$浓度减小, 抑制其与光生电子的复合, 使 开路电压不会大幅降低. Kisserwan 和 Ghaddar ${ }^{142}$ 报 道了 $\mathrm{CuI}$ 作为添加剂对基于离子液体电解质的 DSC 性能影响. 其电催化作用加快了染料的再生从而使 电池的 $J_{\mathrm{sc}}$ 得到提高. $\mathrm{CuI}$ 对 $\mathrm{TiO}_{2}$ /染料/电解质界面的 电子复合不产生影响, 因此电池的 $V_{\mathrm{oc}}$ 基本不变. Zhao 等 ${ }^{130}$ 引入了一种基于苯并咪唑的离子液体添 加剂, 该离子液体作为添加剂应用到 DSC 中, 不仅 有提高了电池的整体性能, 有效抑制了电子复合, 还 保持有更好的稳定性.

准固态电解质近年来也备受研究者们的关注. Huang 等 ${ }^{35}$ 在基于纳米复合硅材料的凝胶电解质中 加入冠醚作为添加剂. 冠醚具有较大的穴半径, 可以 捕获电解质中的 $\mathrm{Li}^{+}$从而使 $\mathrm{LiI}$ 电离而分开, 提高了 $\mathrm{I}$ 的表观扩散系数, 使激发态的染料可以快速还原再 生, 因此电池的 $J_{\mathrm{sc}}$ 和 FF 明显得到提高. 同时暗电流 的减少表明冠醚可以抑制电子复合. Zhu 等 ${ }^{143}$ 将 $\mathrm{Mg}\left(\mathrm{OOCCH}_{3}\right)_{2}$ 引入了基于聚合物凝胶电解质的 $\mathrm{DSC}$ 中, $\mathrm{Mg}\left(\mathrm{OOCCH}_{3}\right)_{2}$ 可以在 $\mathrm{TiO}_{2}$ 表面形成一层阻 挡层抑制了 $\mathrm{TiO}_{2}$ 导带中电子与电解质中 $\mathrm{I}_{3}^{-}$的复合, 因此 $V_{\mathrm{oc}}$ 得到提高. 同时, $\mathrm{Mg}\left(\mathrm{OOCCH}_{3}\right)_{2}$ 与 $\mathrm{N} 3$ 染料的 分子间作用力提高了染料的激发态能级, 增大了电 子的注入效率及 $J_{\mathrm{sc}}$. 笔者研究组 ${ }^{144}$ 在电解质中引入 了一种具有光散射作用的联苯氰类液晶, 这种液晶 既可以作为凝胶剂又可以作为光散射材料, 基于此 准固态电解质的 DSC 在提高稳定性的同时也提高 了染料的光吸收. Zhao 等 ${ }^{145}$ 合成了基于氧基联苯的 苯并咪唑类液晶, 并作为 $\mathrm{TiO}_{2}$ 光阳极的界面修饰功 能材料应用在 DSC 中, 将修饰后的 DSC 与常规含有 电解质添加剂 NBB 的电池进行比较, 结果发现由于 该修饰材料对电子复合的抑制, 电解质的导电性得 到优化, 以及在 $\mathrm{TiO}_{2}$ /染料/电解质界面光吸收的增 强, 使电池的整体性能得到提高.

添加剂对于 $\mathrm{TiO}_{2}$ /染料/电解质界面的修饰作用 主要通过调节 $\mathrm{TiO}_{2}$ 的导带并抑制界面处的电子复 合来实现, 对于越来越多种类的添加剂, 其作用的机 理仍需要进一步完善. 目前添加剂的理论研究大多 数是基于钉染料为敏化剂的太阳电池, 其对基于有 机染料的电池性能作用还有待进一步研究.

\section{5 结论与展望}

对 $\mathrm{TiO}_{2}$ /染料/电解质界面的修饰是解决界面处 电子复合并抑制暗电流的有效方法, 本文总结了从
不同引入途径对 $\mathrm{TiO}_{2}$ /染料/电解质界面修饰方法的 研究进展及机理探讨. 目前很多修饰材料和修饰方 法已经日趋成熟, 但仍有很多基础科学问题需进一 步研究, 很多界面修饰的微观机理尚存在争议.

在对纳晶半导体表面修饰及改性方面, 首先, 从 理论上对 $\mathrm{TiO}_{2}$ 薄膜电极微观结构、缺陷态和杂质能 级等的系统研究较少, 需要建立更加完善的结构模 型, 深入研究对薄膜处理后其内部电子的注入、传输 和复合机制, 为电池性能的优化提供理论指导; 其 次, 设计各种新型结构的纳晶半导体电极及电极材 料微观结构, 对电极进行金属或非金属掺杂, 调控纳 晶半导体的能带结构及微观形貌, 构筑适用于各种 电解质体系的纳晶半导体电极将成为未来太阳电池 效率进一步提高的一个切入点.

通过染料溶液对 $\mathrm{TiO}_{2}$ / 染料/电解质界面的修饰 是改进光阳极界面特性和电池性能的重要途径. 适 当的共吸附剂引入可以避免染料特别是部分有机染 料在纳晶半导体表面的聚集, 并可以调控半导体表 面的带边位置, 从染料溶液引入共吸附剂, 需要根据 染料的结构特点及整个 DSC 电池体系进行选择, 作 为近年来的一个研究热点的新型 D-A 型共吸附剂 的设计与合成还需要探索. 多种染料共敏化即所谓 的 “鸡尾酒染色” 作为弥补单一染料吸光能力不足 的一个有效手段, 是提高染料敏化太阳电池性能的 一个有效途径. 该手段也是目前染料敏化太阳电池 $12.3 \%$ 效率记录中采用的方法. 通过红光至近红外 光区染料和锌卟啉染料或钉配合物染料的适当结 合, 有可能创造染料敏化太阳电池效率的新的世界 记录.

电解质中添加剂的加入也是目前普遍采用的界 面修饰方法. 叔丁基吡啶等含氮杂环化合物是目前 使用较为广泛的电解质添加剂. 该添加剂易于挥发, 给电池密封造成困难, 另外其碱性可能导致有机染 料在纳晶半导体表面的脱附. 寻找稳定且不易挥发 的材料, 在保证电池稳定性的同时, 对添加剂修饰机 理等研究工作还有待进一步深入研究. 最近, 在电解 质中添加小分子液晶或利用小分子液晶直接修饰纳 晶半导体薄膜, 利用其在电解质中长程有序, 能散射 光的特性, 形成具有陷光结构的电解质体系, 将成为 电解质研究的一个热点.

DSC 中电子的产生、注入和传输及复合都发生 $\mathrm{TiO}_{2} /$ 染料/电解质界面处, 因此, 提高 DSC 性能不仅 需要寻求新材料新方法对其界面修饰, 深入的理论 
研究还需要进一步完善.

\section{References}

(1) O'Regan, B.; Grätzel, M. Nature 1991, 353, 737. doi: 10.1038/ $353737 \mathrm{a} 0$

(2) Yella, A.; Lee, H. W.; Tsao, H. N.; Yi, C.; Chandiran, A. K.; Nazeeruddin, M. K.; Diau, E. W. G.; Yeh, C. Y.; Zakeeruddin, S. M.; Grätzel, M. Science 2011, 334, 629. doi: 10.1126/science. 1209688

(3) Grätzel, M. Nature 2001, 414, 338. doi: 10.1038/35104607

(4) Yu, Z. X.; Li, D. M.; Qin, D.; Sun, H. C.; Zhang, Y. D.; Luo, Y. H.; Meng, Q. B. Mater. China 2009, 28, 8. [于哲勋, 李冬梅, 秦 达, 孙惠成, 张一多, 罗艳红, 孟庆波. 中国材料进展, 2009, 28, 8.]

(5) Gong, F.; Zhou, G.; Wang, Z. S. Chin. Sci. Bull. 2013, 58, 294. [宫 峰, 周 刚, 王忠胜. 科学通报, 2013, 58, 294.] doi: 10.1360/972012-1327

(6) Lin, Y.; Wang, S. H.; Fu, N. Q.; Zhang, J. B.; Zhou, X. W.; Xiao, X. R. Prog. Chem. 2011, 23, 548. [林 原, 王尚华, 付年庆, 张敬波, 周晓文, 肖绪瑞. 化学进展, 2011, 23, 548.]

(7) Wu, G. H.; Kong, F. T.; Weng, J.; Dai, S. Y.; Xi, X. W.; Zhang, C. N. Prog. Chem. 2011, 23, 1929. [武国华, 孔凡太, 翁 坚, 戴松元, 奚小网, 张昌能. 化学进展, 2011, 23, 1929.]

(8) Lan, Z.; Wu, J. H.; Lin, J. M.; Huang, M. L. J. Synth. Cryst. 2012, 41, 227. [兰 章, 吴季怀, 林建明, 黄妙良. 人工晶体学 报, 2012, 41, 227.]

(9) Hao, S. C.; Wu, J. H.; Fan, L. Q.; Huang, Y. F.; Lin, H. M.; Wei, Y. L. Sol. Energy 2004, 76, 745. doi: 10.1016/j.solener. 2003.12.010

(10) Wang, Z. S.; Yamaguchi, T.; Sugihara, H.; Arakawa, H. Langmuir 2005, 21, 4272. doi: 10.1021/la050134w

(11) Murayama, M.; Mori, T. Thin Solid Films 2006, 509, 123. doi: 10.1016/j.tsf.2005.09.145

(12) Jung, H. S.; Lee, J. K.; Lee, S.; Hong, K. S.; Shin, H. J. Phys. Chem. C 2008, 112, 8476. doi: 10.1021/jp711689u

(13) Lee, M. K.; Yen, H.; Hsiao, C. C. J. Electrochem. Soc. 2011, $158, \mathrm{~K} 136$

(14) Ko, K. H.; Lee, Y. C.; Jung, Y. J. J. Colloid Interface Sci. 2005, 283, 482. doi: 10.1016/j.jcis.2004.09.009

(15) Kay, A.; Grätzel, M. J. Phys. Chem. 1993, 97, 6272. doi: $10.1021 / \mathrm{j} 100125 \mathrm{a} 029$

(16) Wang, P.; Zakeeruddin, S. M.; Comte, P.; Charvet, R.; HumphryBaker, R.; Grätzel, M. J. Phys. Chem. B 2003, 107, 14336. doi: 10.1021/jp0365965

(17) Wang, P.; Zakeeruddin, S. M.; Humphry-Baker, R.; Moser, J. E.; Grätzel, M. Adv. Mater. 2003, 15, 2101.

(18) Wang, P.; Zakeeruddin, S. M.; Humphry-Baker, R.; Grätzel, M. Chem. Mater. 2004, 16, 2694. doi: 10.1021/cm0499161

(19) Zhang, Z. P.; Zakeeruddin, S. M.; O'Regan, B. C.; HumphryBaker, R.; Grätzel, M. J. Phys. Chem. B 2005, 109, 21818. doi: 10.1021/jp054305h

(20) Kopidakis, N.; Neale, N. R.; Frank, A. J. J. Phys. Chem. B 2006, 110, 12485. doi: 10.1021/jp0607364

(21) Xu, W.; Pei, J.; Shi, J. F.; Peng, S. J.; Chen, J. J. Power Sources 2008, 183, 792. doi: 10.1016/j.jpowsour.2008.05.025

(22) Yum, J. H.; Moon, S. J.; Humphry-Baker, R.; Walter, P.; Geiger, T.; Nuesch, F.; Grätzel, M.; Nazeeruddin, M. K. Nanotechnology 2008, 19, 424005. doi: 10.1088/0957-4484/19/ $42 / 424005$

(23) Allegrucci, A.; Lewcenko, N. A.; Mozer, A. J.; Dennany, L.; Wagner, P.; Officer, D. L.; Sunahara, K.; Mori, S.; Spiccia, L. Energy Environ. Sci. 2009, 2, 1069. doi: 10.1039/b909709k

(24) Marinado, T.; Hahlin, M.; Jiang, X.; Quintana, M.; Johansson, E. M. J.; Gabrielsson, E.; Plogmaker, S.; Hagberg, D. P.; Boschloo, G.; Zakeeruddin, S. M.; Grätzel, M.; Siegbahn, H.; Sun, L.; Hagfeldt, A.; Rensmo, H. J. Phys. Chem. C 2010, 114, 11903. doi: 10.1021/jp102381x

(25) Mikroyannidis, J. A.; Suresh, P.; Roy, M. S.; Sharma, G. D. Electrochim. Acta 2011, 56, 5616. doi: 10.1016/j.electacta. 2011.04 .011

(26) Cid, J. J.; Yum, J. H.; Jang, S. R.; Nazeeruddin, M. K.; MartínezFerrero, E.; Palomares, E.; Ko, J.; Grätzel, M.; Torres, T. Angew. Chem. Int. Edit. 2007, 46, 8358.

(27) Wang, P.; Zakeeruddin, S. M.; Exnar, I.; Grätzel, M. Chem. Commun. 2002, 2972.

(28) Kusama, H.; Konishi, Y.; Sugihara, H.; Arakawa, H. Sol. Energy Mater. Sol. Cells 2003, 80, 167. doi: 10.1016/j.solmat. 2003.08.001

(29) Kusama, H.; Arakawa, H. Sol. Energy Mater. Sol. Cells 2004, 81, 87. doi: 10.1016/j.solmat.2003.09.001

(30) Watson, D. F.; Meyer, G. J. Coord. Chem. Rev. 2004, 248, 1391. doi: 10.1016/j.ccr.2004.02.015

(31) Nakade, S.; Kanzaki, T.; Kambe, S.; Wada, Y. J.; Yanagida, S. Langmuir 2005, 21, 11414. doi: 10.1021/la051483t

(32) Zhang, C.; Dai, J.; Huo, Z.; Pan, X.; Hu, L.; Kong, F.; Huang, Y.; Sui, Y.; Fang, X.; Wang, K.; Dai, S. Electrochim. Acta 2008, 53, 5503. doi: 10.1016/j.electacta.2008.03.016

(33) Zhang, C.; Huang, Y.; Huo, Z.; Chen, S.; Dai, S. J. Phys. Chem. C 2009, 113, 21779. doi: 10.1021/jp909732f

(34) Kim, M. J.; Lee, C. R.; Jeong, W. S.; Im, J. H.; Ryu, T. I.; Park, N. G. J. Phys. Chem. C 2010, 114, 19849. doi: 10.1021/ jp107437h

(35) Huang, K. C.; Vittal, R.; Ho, K. C. Sol. Energy Mater. Sol. Cells 2010, 94, 675. doi: 10.1016/j.solmat.2009.11.002

(36) Ma, B.; Gao, R.; Wang, L.; Zhu, Y.; Shi, Y.; Geng, Y.; Dong, H.; Qiu, Y. Sci. China-Chem. 2010, 53, 1669. doi: 10.1007/s11426010-4042-8

(37) Thavasi, V.; Renugopalakrishnan, V.; Jose, R.; Ramakrishna, S. Mater. Sci. Eng. R 2009, 63, 81. doi: 10.1016/j.mser.2008.09.001

(38) Zhang, Q.; Cao, G. Nano Today 2011, 6, 91. doi: 10.1016/j. nantod.2010.12.007 
(39) Sommeling, P. M.; O'Regan, B. C.; Haswell, R. R.; Smit, H. J. P.; Bakker, N. J.; Smits, J. J. T.; Kroon, J. M.; van Roosmalen, J. A. M. J. Phys. Chem. B 2006, 110, 19191. doi: 10.1021/ jp061346k

(40) O'Regan, B. C.; Durrant, J. R.; Sommeling, P. M.; Bakker, N. J. J. Phys. Chem. C 2007, 111, 14001. doi: 10.1021/jp073056p

(41) Zhuang, D. T.; Lin, H.; Li, X.; Li, J. B. J. Chin. Ceram. Soc. 2010, 38, 1848. [庄东填, 林 红, 李 金銈, 李建保. 硅酸盐学 报, 2010, 38, 1848.]

(42) Kay, A.; Grätzel, M. Chem. Mater. 2002, 14, 2930. doi: 10.1021/ $\mathrm{cm} 0115968$

(43) Feng, Y.; Ji, X.; Duan, J.; Zhu, J.; Jiang, J.; Ding, H.; Meng, G.; Ding, R.; Liu, J.; Hu, A.; Huang, X. J. Solid State Chem. 2012, 190, 303. doi: 10.1016/j.jssc.2012.02.026

(44) Ma, T. L.; Akiyama, M.; Abe, E.; Imai, I. Nano Lett. 2005, 5 , 2543. doi: 10.1021/n10518851

(45) Tian, H.; Hu, L.; Zhang, C.; Liu, W.; Huang, Y.; Mo, L.; Guo, L.; Sheng, J.; Dai, S. J. Phys. Chem. C 2010, 114, 1627. doi: 10.1021/jp9103646

(46) Tian, H.; Hu, L.; Li, W.; Sheng, J.; Xu, S.; Dai, S. J. Mater. Chem. 2011, 21, 7074. doi: 10.1039/c1jm10853k

(47) Tian, H.; Hu, L.; Zhang, C.; Chen, S.; Sheng, J.; Mo, L.; Liu, W.; Dai, S. J. Mater. Chem. 2011, 21, 863. doi: 10.1039/ c0jm02941f

(48) Zhang, X.; Liu, F.; Huang, Q. L.; Zhou, G.; Wang, Z. S. J. Phys. Chem. C 2011, 115, 12665. doi: 10.1021/jp201853c

(49) Gong, J.; Pu, W.; Yang, C.; Zhang, J. Chem. Eng. J. 2012, 209, 94. doi: 10.1016/j.cej.2012.07.137

(50) Barbé, C. J.; Arendse, F.; Comte, P.; Jirousek, M.; Lenzmann, F.; Shklover, V.; Grätzel, M. J. Am. Ceram. Soc. 1997, 80, 3157.

(51) Nazeeruddin, M. K.; Humphry-Baker, R.; Liska, P.; Grätzel, M. J. Phys. Chem. B 2003, 107, 8981. doi: 10.1021/jp022656f

(52) Ito, S.; Liska, P.; Comte, P.; Charvet, R.; Péchy, P.; Bach, U.; Schmidt-Mende, L.; Zakeeruddin, S. M.; Kay, A.; Nazeeruddin, M. K.; Grätzel, M. Chem. Commun. 2005, 4351.

(53) Ito, S.; Murakami, T. N.; Comte, P.; Liska, P.; Grätzel, C.; Nazeeruddin, M. K.; Grätzel, M. Thin Solid Films 2008, 516, 4613. doi: 10.1016/j.tsf.2007.05.090

(54) Nazeeruddin, M. K.; Kay, A.; Rodicio, I.; Humphry-Baker, R.; Müller, E.; Liska, P.; Vlachopoulos, N.; Grätzel, M. J. Am. Chem. Soc. 1993, 115, 6382. doi: 10.1021/ja00067a063

(55) Zeng, L. Y.; Dai, S. Y.; Wang, K. J.; Pan, X.; Shi, C. W.; Guo, L. Chin. Phys. Lett. 2004, 21, 1835. doi: 10.1088/0256-307X/21/9/ 045

(56) Hao, Y. Z.; Wang, L. G. Chin. J. Inorg. Chem. 2007, 23, 2039. [郝彦忠, 王利刚. 无机化学学报, 2007, 23, 2039.]

(57) Hao, Y. Z.; Wang, L. G. Acta Chim. Sin. 2008, 66, 757. [郝彦 忠, 王利刚. 化学学报, 2008, 66, 757.]

(58) Song, M. Y.; Kim, D. K.; Jo, S. M.; Kim, D. Y. Synth. Met. 2005, 155, 635. doi: 10.1016/j.synthmet.2005.08.018

(59) Liu, B.; Aydil, E. S. J. Am. Chem. Soc. 2009, 131, 3985. doi:
$10.1021 / \mathrm{ja} 8078972$

(60) Charoensirithavorn, P.; Ogomi, Y.; Sagawa, T.; Hayase, S.; Yoshikawaa, S. J. Electrochem. Soc. 2010, 157, B354.

(61) Wang, J.; Lin, Z. Chem. Mater. 2010, 22, 579. doi: 10.1021/ $\mathrm{cm} 903164 \mathrm{k}$

(62) Yu, H.; Zhang, S.; Zhao, H.; Xue, B.; Liu, P.; Will, G. J. Phys. Chem. C 2009, 113, 16277. doi: 10.1021/jp9041974

(63) Xu, W. W.; Dai, S. Y.; Fang, X. Q.; Hu, L. H.; Kong, F. T.; Pan, X.; Wang, K. J. Acta Phys. Sin. 2005, 54, 5943. [徐炜炜, 戴松 元, 方霞琴, 胡林华, 孔凡太, 潘 旭, 王孔嘉. 物理学报, 2005, 54, 5943.]

(64) Wang, Z. S.; Li, F. Y.; Huang, C. H. J. Phys. Chem. B 2001, 105, 9210. doi: 10.1021/jp010667n

(65) Alarcón, H.; Boschloo, G.; Mendoza, P.; Solis, J. L.; Hagfeldt, A. J. Phys. Chem. B 2005, 109, 18483. doi: 10.1021/jp0513521

(66) Palomares, E.; Clifford, J. N.; Haque, S. A.; Lutz, T.; Durrant, J. R. J. Am. Chem. Soc. 2003, 125, 475. doi: 10.1021/ja027945w

(67) Kim, J. T.; Kim, S. H. Sol. Energy Mater. Sol. Cells 2011, 95 , 336. doi: 10.1016/j.solmat.2010.04.045

(68) Wu, S. J.; Gao, X. S.; Qin, M. H.; Liu, J. M.; Hu, S. J. Appl. Phys. Lett. 2011, 99, 042106. doi: 10.1063/1.3617460

(69) Antila, L. J.; Heikkilä, M. J.; Mäkinen, V.; Humalamäki, N.; Laitinen, M.; Linko, V.; Jalkanen, P.; Toppari, J.; Aumanen, V.; Kemell, M.; Myllyperkiö, P.; Honkala, K.; Häkkinen, H.; Leskelä, M.; Korppi-Tommola, J. E. I. J. Phys. Chem. C 2011, 115, 16720. doi: 10.1021/jp204886n

(70) Chen, S. G.; Chappel, S.; Diamant, Y.; Zaban, A. Chem. Mater. 2001, 13, 4629. doi: 10.1021/cm010343b

(71) Diamant, Y.; Chen, S. G.; Melamed, O.; Zaban, A. J. Phys. Chem. B 2003, 107, 1977. doi: 10.1021/jp027827v

(72) Diamant, Y.; Chappel, S.; Chen, S. G.; Melamed, O.; Zaban, A. Coord. Chem. Rev. 2004, 248, 1271. doi: 10.1016/j.ccr. 2004.03.003

(73) Wu, S.; Han, H.; Tai, Q.; Zhang, J.; Xu, S.; Zhou, C.; Yang, Y.; Hu, H.; Chen, B.; Zhao, X. Z. J. Power Sources 2008, 182, 119. doi: 10.1016/j.jpowsour.2008.03.054

(74) Jung, H. S.; Lee, J. K.; Nastasi, M.; Lee, S. W.; Kim, J. Y.; Park, J. S.; Hong, K. S.; Shin, H. Langmuir 2005, 21, 10332. doi: $10.1021 / 1 \mathrm{a} 051807 \mathrm{~d}$

(75) Li, W. X.; Hu, L. H.; Dai, S. Y. Acta Phys. -Chim. Sin. 2011, 27, 2367. [李文欣, 胡林华, 戴松元. 物理化学学报, 2011, 27, 2367.] doi: 10.3866/PKU.WHXB20111011

(76) Wang, Z. S.; Yanagida, M.; Sayama, K.; Sugihara, H. Chem Mater. 2006, 18, 2912. doi: 10.1021/cm0603102

(77) Wu, X. M.; Wang, L. D.; Luo, F.; Ma, B.; Zhan, C.; Qiu, Y. J. Phys. Chem. C 2007, 111, 8075. doi: 10.1021/jp0706533

(78) Park, S. K.; Kim, C.; Kim, J. H.; Bae, J. Y.; Han, Y. S. Curr Appl. Phys. 2011, 11, S131.

(79) Alarcón, H.; Hedlund, M.; Johansson, E. M. J.; Rensmo, H.; Hagfeldt, A.; Boschloo, G. J. Phys. Chem. C 2007, 111, 13267. doi: $10.1021 /$ jp072641n 
(80) Yang, S. M.; Kou, H. Z.; Wang, L.; Wang, H. J.; Fu, W. H. Acta Phys. -Chim. Sin. 2009, 25, 1219. [杨术明, 寇慧芝, 汪 玲, 王红军, 付文红. 物理化学学报, 2009, 25, 1219.] doi: 10.3866/ PKU.WHXB20090526

(81) Zhang, C. N.; Chen, S. H.; Mo, L. E.; Huang, Y.; Tian, H. J.; Hu, L. H.; Huo, Z. P.; Dai, S. Y.; Kong, F. T.; Pan, X. J. Phys. Chem. C 2011, 115, 16418. doi: 10.1021/jp2024318

(82) Duan, Y.; Fu, N.; Liu, Q.; Fang, Y.; Zhou, X.; Zhang, J.; Lin, Y. J. Phys. Chem. C 2012, 116, 8888. doi: 10.1021/jp212517k

(83) Chen, H.; Yao, J. H.; Cao, Y. A. Acta Phys. -Chim. Sin. 2012, 28 , 2632. [程 辉, 姚江宏, 曹亚安. 物理化学学报, 2012, 28, 2632.] doi: 10.3866/PKU.WHXB201207301

(84) Liu, J.; Yang, H.; Tan, W.; Zhou, X.; Lin, Y. Electrochim. Acta 2010, 56, 396. doi: 10.1016/j.electacta.2010.08.063

(85) Liu, Q. P.; Huang, H. J.; Zhou, Y.; Duan, Y. D.; Sun, Q. W.; Lin, Y.Acta Phys. -Chim. Sin. 2012, 28, 591. [刘秋平, 黄慧娟, 周 洋, 段彦董, 孙庆文, 林 原. 物理化学学报, 2012, 28, 591.] doi: 10.3866/PKU.WHXB201112161

(86) Wang, M.; Bai, S.; Chen, A.; Duan, Y.; Liu, Q.; Li, D.; Lin, Y. Electrochim. Acta 2012, 77, 54. doi: 10.1016/j.electacta. 2012.05.050

(87) Yang, S. M.; Li, F. Y.; Huang, C. H. Sci. China Ser. B 2003, 33, 59. [杨术明, 李富友, 黄春辉. 中国科学 B 辑, 2003, 33, 59.]

(88) Xu, W. W.; Dai, S. Y.; Hu, L. H.; Liang, L. Y.; Wang, K. J. Chin. Phys. Lett. 2006, 23, 2288. doi: 10.1088/0256-307X/23/8/089

(89) Kim, S. K.; Son, M. K.; Kim, J. K.; Kim, B. M.; Hong, N. Y.; Prabakar, K.; Kim, H. J. J. Jpn. Inst. Met. 2012, 51, 09MA05-1.

(90) Li, J.; Kong, F. T.; Wu, G. H.; Zhang, C. N.; Dai, S. Y. Acta Phys. -Chim. Sin. 2011, 27, 881. [李 洁, 孔凡太, 武国华, 张 昌能, 戴松元. 物理化学学报, 2011, 27, 881.] doi: 10.3866/ PKU.WHXB20110413

(91) Li, J.; Wu, W.; Yang, J.; Tang, J.; Long, Y.; Hua, J. Sci. China Chem. 2011, 54, 699

(92) Sharma, G. D.; Kurchania, R.; Ball, R. J.; Roy, M. S.; Mikroyannidis, J. A. Int. J. Photoenergy 2012, 2012, 983081

(93) Zhang, Z.; Evans, N.; M.Zakeeruddin, S.; Hunphry-Baker, R.; Grätzel, M. J. Phys. Chem. B 2007, 111, 398

(94) Li, X.; Lin, H.; Zakeeruddin, S. M.; Grätzel, M.; Li, J. Chem. Lett. 2009, 38, 322. doi: 10.1246/c1.2009.322

(95) Kwon, Y. S.; Song, I. Y.; Lim, J.; Park, S. H.; Siva, A.; Park, Y. C.; Jang, H. M.; Park, T. RSC Adv. 2012, 2, 3467. doi: 10.1039/ c2ra01251k

(96) Galoppini, E. Coord. Chem. Rev. 2004, 248, 1283. doi: 10.1016/ j.ccr.2004.03.016

(97) Wang, M.; Li, X.; Lin, H.; Pechy, P.; Zakeeruddin, S. M.; Grätzel, M. Dalton Trans. 2009, 45, 10015

(98) Li, X.; Lin, H.; Li, J. B. Rare Metal Mat. Eng. 2009, 38 (Suppl. 2), 1047. [李 金金, 林 红, 李建保. 稀有金属材料与工程, 2009, 38 (Suppl. 2), 1047.]

(99) Shen, H.; Lin, H.; Liu, Y.; Li, X.; Zhang, J.; Wang, N.; Li, J. Electrochim. Acta 2011, 56, 2092. doi: 10.1016/j. electacta.2010.11.087

(100) Lin, H.; Liu, Y.; Liu, C.; Li, X.; Shen, H.; Zhang, J.; Ma, T.; Li, J. J. Electroanal. Chem. 2011, 653, 81.

(101) Song, B. J.; Song, H. M.; Choi, I. T.; Kim, S. K.; Seo, K. D.; Kang, M. S.; Lee, M. J.; Cho, D. W.; Ju, M. J.; Kim, H. K. Chem. Eur. J. 2011, 17, 11115. doi: 10.1002/chem.201100813

(102) Han, L.; Islam, A.; Chen, H.; Malapaka, C.; Chiranjeevi, B.; Zhang, S.; Yang, X.; Yanagida, M. Energy Environ. Sci. 2012, 5, 6057. doi: 10.1039/c2ee 03418b

(103) Hara, K.; Dan-Oh, Y.; Kasada, C.; Ohga, Y.; Shinpo, A.; Suga, S.; Sayama, K.; Arakawa, H. Langmuir 2004, 20, 4205. doi: 10.1021/la0357615

(104) Neale, N. R.; Kopidakis, N.; van de Lagemaat, J.; Grätzel, M.; Frank, A. J. J. Phys. Chem. B 2005, 109, 23183. doi: 10.1021/ jp0538666

(105) Wang, Z. S.; Cui, Y.; Dan-Oh, Y.; Kasada, C.; Shinpo, A.; Hara, K. J. Phys. Chem. C 2007, 111, 7224. doi: 10.1021/ jp067872t

(106) Ren, X.; Feng, Q.; Zhou, G.; Huang, C. H.; Wang, Z. S. J. Phys. Chem. C 2010, 114, 7190. doi: 10.1021/jp911630z

(107) Kuang, D.; Walter, P.; Nüeesch, F.; Kim, S.; Ko, J.; Comte, P.; Zakeeruddin, S. M.; Nazeeruddin, M. K.; Grätzel, M. Langmuir 2007, 23, 10906. doi: 10.1021/1a702411n

(108) Bessho, T.; Zakeeruddin, S. M.; Yeh, C. Y.; Diau, E. W. G.; Grätzel, M. Angew. Chem. Int. Edit. 2010, 49, 6646. doi: 10.1002/anie.201002118

(109) Fan, S. Q.; Kim, C.; Fang, B.; Liao, K. X.; Yang, G. J.; Li, C. J.; Kim, J. J.; Ko, J. J. Phys. Chem. C 2011, 115, 7747. doi: 10.1021/jp200700e

(110) Lee, K. M.; Hsu, Y. C.; Ikegami, M.; Miyasaka, T.; Thomas, K R. J.; Lin, J. T.; Ho, K. M. J. Power Sources 2011, 196, 2416. doi: 10.1016/j.jpowsour.2010.10.041

(111) Akhtaruzzaman, M.; Islam, A.; Karim, M. R.; Hasan, A. K. M.; Han, L. J. Chem. 2012, 2013, 910527.

(112) Chen, Y. S.; Zeng, Z. H.; Li, C.; Wang, W. B.; Wang, X. S.; Zhang, B. W. New J. Chem. 2005, 29, 773. doi: 10.1039/ b502725j

(113) Li, C.; Zhou, J. H.; Chen, J. R.; Chen, Y. S.; Zhang, X. H.; Ding, H. Y.; Wang, W. B.; Wang, X. S.; Zhang, B. W. Chin. J. Chem. 2006, 24, 537.

(114) Zuo, P.; Li, C.; Wu, Y. S.; Ai, X. C.; Wang, X. S.; Zhang, B. W.; Zhang, J. P. J. Photochcm. Photobiol. A 2006, 183, 138. doi: 10.1016/j.jphotochem.2006.03.007

(115) Song, X. R.; Wang, W. B.; Zhang, X. H.; Li, C.; Wang, X. S.; Zhang, B. W. Acta Chim. Sin. 2008, 66, 1687. [宋晓睿, 王维 波, 张雪华, 李 超, 王雪松, 张宝文. 化学学报, 2008, 66, 1687.]

(116) Nguyen, L. H.; Mulmudi, H. K.; Sabba, D.; Kulkarni, S. A.; Batabyal, S. K.; Nonomura, K.; Grätzel, M.; Mhaisalkar, S. G. Phys. Chem. Chem. Phys. 2012, 14, 16182. doi: 10.1039/ c2cp42959d 
(117) Huang, S. Y.; Schlichthörl, G.; Nozik, A. J.; Grätzel, M.; Frank, A. J. J. Phys. Chem. B 1997, 101, 2576. doi: 10.1021/ jp962377q

(118) Boschloo, G.; Häggman, L.; Hagfeldt, A. J. Phys. Chem. B 2006, 110, 13144. doi: 10.1021/jp0619641

(119) Shi, C. W.; Dai, S. Y.; Wang, K. J.; Pan, X.; Kong, F. T.; Hu, L. H. Vib. Spectrosc. 2005, 39, 99. doi: 10.1016/j.vibspec. 2005.01.002

(120) Greijer, H.; Lindgren, J.; Hagfeldt, A. J. Phys. Chem. B 2001, 105, 6314. doi: 10.1021/jp011062u

(121) Wang, Z. S.; Hara, K.; Dan-Oh, Y.; Kasada, C.; Shinpo, A.; Suga, S.; Arakawa, H.; Sugihara, H. J. Phys. Chem. B 2005, 109, 3907. doi: 10.1021/jp044851v

(122) Wang, Z. S.; Cui, Y.; Dan-oh, Y.; Kasada, C.; Shinpo, A.; Hara, K. J. Phys. Chem. C 2007, 111, 7224. doi: 10.1021/jp067872t

(123) Pei, J.; Peng, S.; Jifu, S.; Liang, Y.; Tao, Z.; Liang, J.; Chen, J. J. Power Sources 2009, 187, 620. doi: 10.1016/j.jpowsour. 2008.11.028

(124) Yin, X.; Zhao, H.; Chen, L.; Tan, W.; Zhang, J.; Weng, Y.; Shuai, Z.; Xiao, X.; Zhou, X.; Li, X.; Lin, Y. Surf. Interface Anal. 2007, 39, 809.

(125) Yin, X.; Tan, W.; Zhang, J.; Weng, Y.; Xiao, X.; Zhou, X.; Li, X.; Lin, Y. Colloid Surface A 2008, 326, 42. doi: 10.1016/j. colsurfa.2008.05.013

(126) Boschloo, G.; Lindström, J.; Magnusson, E.; Holmberg, A.; Hagfeldt, A. J. Photochem. Photobiol. A 2002, 148, 11. doi: 10.1016/S1010-6030(02)00072-2

(127) Boschloo, G.; Hagfeldt, A. Chem. Phys. Lett. 2003, 370, 381 doi: 10.1016/S0009-2614(03)00029-0

(128) Yang, H.; Liu, J.; Lin, Y.; Zhang, J.; Zhou, X. Electrochim. Acta 2011, 56, 6271. doi: 10.1016/j.electacta.2011.05.054

(129) Kuang, D. B.; Klein, C.; Ito, S.; Moser, J. E.; Humphry-Baker, R.; Evans, N.; Duriaux, F.; Grätzel, C.; Zakeeruddin, S. M.; Grätzel, M. Adv. Mater. 2007, 19, 1133.

(130) Zhao, J.; Yan, F.; Qiu, L.; Zhang, Y.; Chen, X.; Sun, B. Chem. Commun. 2011, 47, 11516. doi: 10.1039/c1cc15069c

(131) Shi, C. W.; Ge, Q.; Li, B.; Tao, L.; Liu, Q. A. Acta Phys. -
Chim. Sin. 2008, 24, 2327. [史成武, 葛 茜, 李 兵, 桃 李, 刘清安. 物理化学学报, 2008, 24, 2327.] doi: 10.3866/ PKU.WHXB20081230

(132) Kusama, H.; Kurashige, M.; Arakawa, H. J. Photochem. Photobiol. A 2005, 169, 169. doi: 10.1016/j.jphotochem. 2004.06.012

(133) Kusama, H.; Arakawa, H. Sol. Energy Mater. Sol. Cells 2005, 85, 333. doi: 10.1016/j.solmat.2004.05.003

(134) Kelly, C. A.; Farzad, F.; Thompson, D. W.; Stipkala, J. M.; Meyer, G. J. Langmuir 1999, 15, 7047. doi: 10.1021/la990617y

(135) Kopidakis, N.; Benkstein, K. D.; van de Lagemaat, J.; Frank, A. J. J. Phys. Chem. B 2003, 107, 11307.

(136) Koops, S. E.; O'Regan, B. C.; Barnes, P. R. F.; Durrant, J. R. J. Am. Chem. Soc. 2009, 131, 4808. doi: 10.1021/ja8091278

(137) Stergiopoulos, T.; Rozi, E.; Karagianni, C. S.; Falaras, P. Nanoscale Res. Lett. 2011, 6, 307. doi: 10.1186/1556-276X-6307

(138) Liu, X.; Qin, D.; Fan, Y.; Li, K.; Li, D.; Meng, Q. Electrochem Commun. 2007, 9, 1735. doi: 10.1016/j.elecom.2007.03.029

(139) Shi, C. W.; Dai, S. Y.; Wang, K. J.; Pan, X.; Guo, L.; Hu, L. H.; Kong, F. T. Chin. J. Chem. 2005, 23, 251.

(140) Raja, S.; Satheeshkumar, C.; Rajakumar, P.; Ganesan, S.; Maruthamuthu, P. J. Mater. Chem. 2011, 21, 7700. doi: 10.1039/c1jm10334b

(141) Cai, M.; Pan, X.; Liu, W.; Sheng, J.; Fang, X.; Zhang, C.; Huo, Z.; Tian, H.; Xiao, S.; Dai, S. J. Mater. Chem. A 2013, 1,4885. doi: $10.1039 / \mathrm{c} 3 \mathrm{ta} 00835 \mathrm{e}$

(142) Kisserwan, H.; Ghaddar, T. H. Dalton Trans. 2011, 40, 3877. doi: 10.1039/c0dt01554g

(143) Zhu, Y.; Shi, Y.; Wang, L.; Gao, R.; Ma, B.; Geng, Y.; Qiu, Y. Phys. Chem. Chem. Phys. 2010, 12, 15001. doi: 10.1039/ c004372a

(144) Wang, M.; Pan, X.; Fang, X.; Guo, L.; Liu, W.; Zhang, C.; Huang, Y.; Hu, L.; Dai, S. Adv. Mater. 2010, 22, 5526. doi: 10.1002/adma.v22.48

(145) Zhao, J.; Sun, B.; Qiu, L.; Caocen, H.; Li, Q.; Chen, X.; Yan, F. J. Mater. Chem. 2012, 22, 18380. doi: 10.1039/c2jm32607h 